\title{
Definition by Induction in Frege's Grundgesetze der Arithmetik
}

Richard G. Heck, Jnr. Department of Philosophy Harvard University

Published in W. Demopoulos, ed.

Frege's Philosophy of Mathematics

Cambridge MA: Harvard University Press, 1995, pp. 295-333, and Reprinted in M. Schirn, ed., Frege: Tradition and Influence

New York: de Gruyter, 1996, pp. 200-33

This is the manuscript on which the published version was based. There may be, and almost certainly are, differences in the text. 


\section{Opening}

Dedekind's Was Sind und Was Sollen die Zahlen? has long been celebrated for the proofs of two important theorems. The first of these is the proof of the validity of the definition, by induction, of a function defined on the natural numbers, that is, of the recursion theorem for $\omega$. The second is the proof that all "simply infinite systems"--that is, structures which satisfy the Dedekind-Peano axioms--are isomorphic. ${ }^{1}$ Dedekind's proofs of these theorems are carried out set-theoretically, the set theory in question being unformalized. It is well-known that the proofs of these theorems can be carried out in second-order arithmetic or in standard set-theories, and Dedekind is usually credited with having been the first to give a set-theoretic proof of these results.

It is almost unknown, however, that, in his Grundgesetze der Arithmetik, ${ }^{2}$ Frege gives formal proofs of both of these results. Of course, the formal system of Grundgesetze is inconsistent, Russell's Paradox being derivable, in second-order logic, from Frege's infamous Axiom V. For present purposes, Axiom V may be taken to be:

$$
(\dot{\varepsilon} . \mathrm{F} \epsilon=\dot{\varepsilon} \cdot \mathrm{G} \epsilon) \equiv \forall \mathrm{x}(\mathrm{Fx} \equiv \mathrm{Gx})
$$

Axiom V, so formulated, governs terms which purport to stand for the extensions of concepts, ${ }^{3}$ and such terms occur throughout Grundgesetze. As I have shown elsewhere, however, Frege makes reference to value-ranges, for the most part, only for convenience, and such reference may be eliminated, uniformly, from the great majority of his proofs. ${ }^{4}$

Frege makes essential use of Axiom $\mathrm{V}$ only in his proof of what has come to be known as Hume's Principle. Hume's Principle may be formalized in second-order logic as:

$$
\begin{aligned}
\text { Nx:Fx }=\text { Nx:Gx iff }(\exists \mathrm{R}) & {[\forall \mathrm{x} \forall \mathrm{y} \forall \mathrm{z}(\mathrm{Rxy} \& \mathrm{Rxz} \rightarrow \mathrm{y}=\mathrm{z}) \&} \\
& \forall \mathrm{x} \forall \mathrm{y} \forall \mathrm{z}(\mathrm{Rxz} \& \mathrm{Ryz} \rightarrow \mathrm{x}=\mathrm{y}) \& \\
& \forall \mathrm{x}(\mathrm{Fx} \rightarrow \exists \mathrm{y}(\mathrm{Rxy} \& \mathrm{~Gy})) \& \\
& \forall \mathrm{x}(\mathrm{Gx} \rightarrow \exists \mathrm{y}(\mathrm{Ryx} \& \mathrm{Fy}))]
\end{aligned}
$$

The second-order theory whose sole "non-logical" axiom is Hume's Principle we may call Fregean Arithmetic: Fregean Arithmetic is equi-consistent with second-order arithmetic and is thus almost certainly consistent. ${ }^{5}$ Frege's proofs of the axioms of arithmetic, in Grundgesetze, can thus be reconstructed as proofs in Fregean Arithmetic: Indeed, it can be argued that Frege knew full well that the 
axioms of arithmetic are derivable, in second-order logic, from Hume's Principle. That is to say: The main theorem of Grundgesetze, which George Boolos has rightly urged us to call Frege's Theorem, is that Hume's Principle implies the axioms of second-order arithmetic.

That Frege offered proofs of the axioms of arithmetic in Grundgesetze is well-known, even if the fact that he proved Frege's Theorem has not been. However, only one-third of Part II of Grundgesetze, entitled "Proofs of the Basic Laws of Number", is concerned with the proofs of these axioms. The remainder of Part II contains proofs of a number of additional results, among them Theorem 167, that there is an infinite cardinal (namely, the number of natural numbers); Theorem 359, of which the least number principle is an instance; and Theorem 469, the main theorem required for the definition of addition. Of interest to us here is Theorem 263.

To state Theorem 263 and the form of Hume's Principle which Frege employs in his proof of it, we need a number of definitions. These definitions, and the theorems themselves, I give in translation into second-order logic. The first is that of the converse of a relation ( $G g$ I §39): ${ }^{6}$

$$
\operatorname{Conv}_{\alpha \epsilon}(\mathrm{R} \alpha \epsilon)(\mathrm{x}, \mathrm{y}) \equiv \mathrm{df} \operatorname{Ryx}
$$

Thus, $\mathrm{x}$ stands in the converse of the relation $\mathrm{R} \xi \eta$ to $\mathrm{y}$ if $\mathrm{y}$ stands in the relation $\mathrm{R} \xi \eta$ to $\mathrm{x}$. The second definition is the familiar one of the functionality of a relation $(G g$ I §37):

$$
\text { Func }_{\alpha \epsilon}(\mathrm{R} \alpha \epsilon) \equiv \mathrm{df} \forall \mathrm{x} \forall \mathrm{y} \forall \mathrm{z}(\mathrm{Rxy} \& \mathrm{Rxz} \rightarrow \mathrm{y}=\mathrm{z})
$$

The third is that of a relation's mapping one concept into another $(G g$ I $\S 38)$ :

$$
\operatorname{Map}_{\alpha \epsilon x y}(R \alpha \epsilon)(F x, G y) \equiv d f F \operatorname{Func}_{\alpha \epsilon}(\mathrm{R} \alpha \epsilon) \& \forall \mathrm{x}[\mathrm{Fx} \rightarrow \exists \mathrm{y}(\mathrm{Rxy} \& \mathrm{~Gy})]
$$

Thus, a relation $R \xi \eta$ maps a concept $F \xi$ into a concept $G \xi$ just in case $R \xi \eta$ is functional and every $F$ stands in it to some (and therefore exactly one) G. ${ }^{7}$ Using these definitions, Frege concisely formulates Hume's Principle as:

$$
\mathrm{Nx}: F x=N x: G x \text { iff }(\exists R)[M a p(R)(F, G) \& \operatorname{Map}(\operatorname{Conv} R)(G, F)]
$$

This formulation is equivalent to the more familiar formulation given above, but it has certain technical advantages over it. ${ }^{8}$

Additionally, we need Frege's famous definition of the strong ancestral of a relation $(G g$ I $\S 45)$ :

$$
\mathscr{F}_{\alpha \epsilon}(\mathrm{Q} \alpha \epsilon)(\mathrm{a}, \mathrm{b}) \equiv \mathrm{df} \forall \mathrm{F}[\forall \mathrm{x}(\mathrm{Q} a x \rightarrow \mathrm{Fx}) \& \forall \mathrm{x} \forall \mathrm{y}(\mathrm{Fx} \& \mathrm{Qxy} \rightarrow \mathrm{Fy}) \rightarrow \mathrm{Fb}]
$$


That is, $b$ follows after $a$ in the $Q$-series if, and only if, b falls under every concept (i) under which all objects to which a stands in the Q-relation fall and (ii) which is hereditary in the $Q$-series, i.e., under which every object to which an F stands in the Q-relation falls. Frege defines the weak ancestral as follows $(G g$ I $\$ 46)$ :

$$
\mathscr{F}={ }_{\alpha \epsilon}(\mathrm{Q} \alpha \epsilon)(\mathrm{a}, \mathrm{b}) \equiv \mathrm{df} \mathscr{F}_{\alpha \epsilon}(\mathrm{Q} \alpha \epsilon)(\mathrm{a}, \mathrm{b}) \vee \mathrm{a}=\mathrm{b}
$$

Thus, $b$ belongs to (or is a member of) the Q-series beginning with a if, and only if, either $\mathrm{b}$ follows after $\mathrm{a}$ in the $\mathrm{Q}$-series or $\mathrm{b}$ is identical with $\mathrm{a}$.

We now turn to the definitions of more particularly arithmetical notions. The number zero is defined by Frege as the number of objects which are not self-identical ( $G g$ I $\$ 41$; see $G l \S 74){ }^{9}$

$$
0=\mathrm{Nx}: \mathrm{X} \neq \mathrm{X}
$$

The relation of predecession is defined as $(G g$ I $\$ 43$; see $G l \S 74)$ :

$$
\operatorname{Pred}(m, n) \equiv d f \exists F \exists y[n=N x: F x \& F y \& m=N x:(F x \& x \neq y)]
$$

That is, $m$ immediately precedes $n$ in the number-series if, and only if, there is some concept $\mathrm{F} \xi$, whose number is $\mathrm{n}$, and an object $\mathrm{y}$ falling under $\mathrm{F} \xi$, such that $\mathrm{m}$ is the number of Fs other than $\mathrm{y}$. The concept of a finite or natural number may then be defined as: ${ }^{10}$

$$
\mathbb{N x} \equiv \mathrm{df} \mathscr{F}^{=}(\operatorname{Pred})(0, \mathrm{x})
$$

So a number is a natural number, is finite, if, and only if, it belongs to the Pred-series (the number-series) beginning with zero. (Famously, induction is a near immediate consequence of this definition.) And, finally, the first transfinite number, which Frege calls "Endlos", may be defined as ( $G g$ I 122):

$$
\infty=\mathrm{df} \mathrm{Nx}: \mathscr{F}=(\text { Pred })(0, \mathrm{x})
$$

Thus, Endlos is the number of natural numbers.

Theorem 263 may then be formulated as:

$$
\begin{aligned}
& \exists \mathrm{Q}[\mathrm{Func}(\mathrm{Q}) \& \neg \exists \mathrm{x} . \mathscr{F}(\mathrm{Q})(\mathrm{x}, \mathrm{x}) \& \forall \mathrm{x}(\mathrm{Gx} \rightarrow \exists \mathrm{y} . \mathrm{Qxy}) \& \exists \mathrm{x} \forall \mathrm{y}(\mathrm{Gy} \equiv \mathscr{T}=(\mathrm{Q})(\mathrm{x}, \mathrm{y}))] \rightarrow \\
& \mathrm{Nx}: \mathrm{Gx}=\infty
\end{aligned}
$$

Suppose that there is a relation $\mathrm{Q} \xi \eta$ which satisfies the following conditions: First, it is functional; second, no object follows after itself in the Q-series; thirdly, each G stands in the Q-relation to some object; and, finally, the Gs are the members of the Q-series beginning with some object. Then, says Theorem 263, the number of Gs is Endlos. 


\section{Frege's Proof of Theorem 263}

It is worth quoting Frege's initial explanation of Theorem 263 in full: ${ }^{11}$

We now prove...that Endlos is the number which belongs to a concept, if the objects falling under this concept may be ordered in a series, which begins with a particular object and continues without end, without coming back on itself and without branching.

By an "unbranching series", Frege means one whose determining relation is functional; by a series which does not "come back on itself", he means one in which no object follows after itself; by a series which "continues without end", he means one every member of which is immediately followed by some object.

What it is essential to show is that Endlos is the number which belongs to the concept member of such a series.... For this purpose, we use proposition (32) and have to establish that there is a relation which maps the number-series into the $Q$-series beginning with $x$, and whose converse maps the latter into the former.

Proposition (32) is one direction of Hume's Principle, namely: If there is a relation which maps the Fs into the Gs and whose converse maps the Gs into the Fs, then the number of Fs is the same as the number of Gs.

It suggests itself to associate 0 with $x, 1$ with the next member of the $Q$-series following after $x$, and so always to associate the number following next with the member of the $Q$ series following next. Each time, we combine a member of the number-series and a member of the $Q$-series into a pair, and we build a series from these pairs.

That is, the theorem is to be proven by defining, by induction, a relation ${ }^{12}$ between the numbers and the members of the $\mathrm{Q}$-series beginning with $\mathrm{x}$ : The number, $n$, which is the immediate successor of a given number, $m$, will be related to that member of Q-series, call it $\mathrm{x}_{\mathrm{n}}$, which follows immediately after the member of the Q-series to which $m$ is related, say, $\mathrm{x}_{\mathrm{m}}$ :

$$
\begin{array}{llll}
0 \rightarrow & 1 \rightarrow & 2 \rightarrow \ldots \rightarrow \mathrm{m} \rightarrow & \mathrm{n} \rightarrow \ldots \\
\mathrm{x}_{0} \rightarrow & \mathrm{x}_{1} \rightarrow & \mathrm{x}_{2} \rightarrow \ldots \rightarrow \mathrm{x}_{\mathrm{m}} \rightarrow & \mathrm{x}_{\mathrm{n}} \rightarrow \ldots
\end{array}
$$

The proof of the theorem will require a proof of the validity of such definitions. The idea is to define the relation by defining a series of ordered pairs: Namely, the series $\left\langle 0 ; \mathrm{x}_{0}\right\rangle,\left\langle 1 ; \mathrm{x}_{1}\right\rangle$, etc. The relation will then hold between objects $\mathrm{x}$ and $\mathrm{y}$ just in case $\langle\mathrm{x} ; \mathrm{y}\rangle$ is a member of this series of ordered pairs; as one 
might put it, the members of this series will be the extension of the relation to be defined. To define this series of ordered pairs, Frege thus needs to introduce ordered pairs into his system and to define the relation in which a given member of the series stands to the next member of the series.

Unfortunately, Frege's definition of ordered pairs is, as George Boolos once put it, extravagant and can not be consistently reconstructed, either in second-order logic or in set-theory. According to Frege's definition, the ordered pair $(a ; b)$ is the class to which all and only the extensions of relations in which a stands to $\mathrm{b}$ belong. Obviously, this is a (super-)proper class. Frege's proof can, however, be carried out if we take ordered pairs as primitive and subject to the usual ordered pair axiom:

$$
\text { OP: }(a ; b)=(c ; d) \equiv[a=c \& b=d]
$$

Indeed, Frege derives OP from his definition, ${ }^{13}$ and the fact that ordered pairs, so defined, satisfy OP is all he really uses (just as the fact that numbers satisfy Hume's Principle is all he uses). ${ }^{14}$

After introducing ordered pairs, Frege continues by defining the relation in which a given member of his series of pairs stands to the next: ${ }^{15}$

The series-forming relation is thereby determined: a pair stands in it to a second pair, if the first member of the first pair stands in the Pred-relation to the first member of the second pair, and the second member of the first pair stands in the $Q$-relation to the second member of the second pair. If, then, the pair $(n ; y)$ belongs to our series beginning with the pair $(0 ; x)$, then $n$ stands to $y$ in the mapping relation to be exhibited.

That is to say: (m;n) will stand in the "series-forming relation" to (x;y) just in case Pred(m,n) and Qxy. Frege goes on to define this relation for the general case:

...For the...relation, which, in the way given above, is, as I say, coupled from the $R$ relation and the $Q$-relation, I introduce a simple sign, by defining:

$$
\Sigma_{\xi \eta \zeta \tau}(\mathrm{R} \xi \eta, \mathrm{Q} \zeta \tau)(\mathrm{a}, \mathrm{b}) \equiv \mathrm{df} \exists \mathrm{x} \exists \mathrm{y} \exists \mathrm{z} \exists \mathrm{w}[\mathrm{a}=(\mathrm{x} ; \mathrm{y}) \& \mathrm{~b}=(\mathrm{z} ; \mathrm{w}) \& \mathrm{Rxz} \& \text { Qyw) }]
$$

If, then, we have a series $\mathrm{x}_{0}, \mathrm{x}_{1}$, etc., where $\mathrm{Qx} \mathrm{x}_{\mathrm{m}+1}$, we have also that $\Sigma(\operatorname{Pred}, \mathrm{Q})\left[\left(0 ; \mathrm{x}_{0}\right),\left(1 ; \mathrm{x}_{1}\right)\right]$, since $\operatorname{Pred}(0,1)$ and $\mathrm{Qx}_{0} \mathrm{x}_{1} ;$ similarly, $\Sigma(\operatorname{Pred}, \mathrm{Q})\left[\left(1 ; \mathrm{x}_{1}\right),\left(2 ; \mathrm{x}_{2}\right)\right]$. Note, however, that we also have $\Sigma\left(\right.$ Pred,Q) $\left[\left(0 ; \mathrm{x}_{16}\right),\left(1 ; \mathrm{x}_{17}\right)\right]$, since $\operatorname{Pred}(0,1)$ and $\mathrm{Qx}_{16} \mathrm{x}_{17}$. To define the wanted relation, we therefore need to restrict attention to members of the series $\left(0 ; \mathrm{x}_{0}\right),\left(1 ; \mathrm{x}_{1}\right),\left(2 ; \mathrm{x}_{2}\right)$, etc. As always, Frege employs the ancestral for this purpose: 
Accordingly,

$$
\mathscr{F}=[\Sigma(\operatorname{Pred}, \mathrm{Q})]\left[\left(0 ; \mathrm{x}_{0}\right),(\xi ; \eta)\right]
$$

indicates our mapping relation....

The relation in question is thus that in which $\xi$ stands to $\eta$ just in case the ordered pair $(\xi ; \eta)$ belongs to the $\Sigma$ (Pred,Q)-series beginning with (0;x). It can indeed be proven that, under the hypotheses of Theorem 263, this relation maps the natural numbers into the members of the Q-series beginning with $\mathrm{x}$ and that its converse maps the latter into the former. Thus, in terms of ordered pairs and his definition of the coupling of two relations, Frege is able explicitly to define a relation which correlates the Gs one-toone with the natural numbers.

\section{Frege's Use of Ordered Pairs}

As said, Frege's proof of Theorem 263 can be carried out in Fregean Arithmetic, if we add the ordered pair axiom to it. More interestingly, however, the proof can also be carried out in Fregean Arithmetic itself.

Frege introduces ordered pairs for two reasons. First, he uses them to give his definition of the coupling of two relations. The use of ordered pairs is obviously inessential to this definition, which can instead be given as: ${ }^{16}$

$$
(\mathrm{R} \pi \mathrm{Q})(\mathrm{a}, \mathrm{b} ; \mathrm{c}, \mathrm{d}) \equiv \mathrm{df} \operatorname{Rac} \& \mathrm{Qbd}
$$

Secondly, as we saw, the relation which is to correlate the natural numbers one-one with the Gs is defined by Frege as:

$$
\mathscr{T}=[\Sigma(\operatorname{Pred}, \mathrm{Q})][(0 ; \mathrm{x}),(\xi ; \eta)]
$$

Thus, Frege uses ordered pairs in order to be able to use the ancestral--which is the ancestral of a twoplace relation--to define this new relation. Given our definition of (R $\pi \mathrm{Q})(\xi, \eta ; \zeta, \tau)$, it is a four-place relation, so we can not apply Frege's definition of the ancestral.

As mentioned, Frege essentially uses nothing about ordered pairs in his proofs other than that they satisfy the ordered pair axiom: Indeed, much of his effort is devoted to eliminating reference to ordered pairs from certain of his theorems. A particularly nice example is an instance of induction for 
series determined by the couplings of relations. The definition of the strong ancestral yields the following, Frege's Theorem 123:

$\mathscr{F}(\mathrm{Q})(\mathrm{a}, \mathrm{b}) \& \forall \mathrm{x} \forall \mathrm{y}(\mathrm{Fx} \& \mathrm{Qxy} \rightarrow \mathrm{Fy}) \& \forall \mathrm{x}(\mathrm{Qax} \rightarrow \mathrm{Fx}) \rightarrow \mathrm{Fb}$

Taking $\mathrm{Q} \xi \eta$ to be $\Sigma(\mathrm{R}, \mathrm{Q})(\xi, \eta)$; a to be $(\mathrm{a} ; \mathrm{b}) ; \mathrm{b}$ to be $(\mathrm{c} ; \mathrm{d})$; we have:

$\mathscr{T}[\Sigma(\mathrm{R}, \mathrm{Q})][(\mathrm{a} ; \mathrm{b}),(\mathrm{c} ; \mathrm{d})] \& \forall \mathrm{x} \forall \mathrm{y}(\mathrm{Fx} \& \Sigma(\mathrm{R}, \mathrm{Q})(\mathrm{x}, \mathrm{y}) \rightarrow \mathrm{Fy}] \&$ $\forall \mathrm{x}[\Sigma(\mathrm{R}, \mathrm{Q})[(\mathrm{a} ; \mathrm{b}), \mathrm{x}] \rightarrow \mathrm{Fx}] \rightarrow \mathrm{F}[(\mathrm{c} ; \mathrm{d})]$

Here, the bound variables will range, for all intents and purposes, over ordered pairs, since the domain and range of $\Sigma(\mathrm{R}, \mathrm{Q})(\xi, \eta)$ consist only of ordered pairs; $\mathrm{F} \xi$, in turn, will be a concept under which ordered pairs fall. Let us define the concept $\mathrm{Col}_{\eta \zeta}(\mathrm{F} \eta \zeta)(\xi)$--the collapse of $\mathrm{F} \xi \eta$--to be that concept under which an ordered pair (x;y) stands just in case Fxy. Formally:

$$
\operatorname{Col}_{\alpha \epsilon}(\mathrm{F} \alpha \epsilon)(\mathrm{a}) \equiv \mathrm{df} \exists \mathrm{x} \exists \mathrm{y}[\mathrm{a}=(\mathrm{x} ; \mathrm{y}) \& \mathrm{Fxy}]
$$

We then substitute $\operatorname{Col}(\mathrm{F})(\xi)$ for $\mathrm{F} \xi$ to get $(*)$ :

$$
\begin{gathered}
\mathscr{F}[\Sigma(\mathrm{R}, \mathrm{Q})][(\mathrm{a} ; \mathrm{b}),(\mathrm{c} ; \mathrm{d})] \& \forall \mathrm{x} \forall \mathrm{y}(\operatorname{Col}(\mathrm{F})(\mathrm{x}) \& \Sigma(\mathrm{R}, \mathrm{Q})(\mathrm{x}, \mathrm{y}) \rightarrow \operatorname{Col}(\mathrm{F})(\mathrm{y})] \& \\
\forall \mathrm{x}[\Sigma(\mathrm{R}, \mathrm{Q})[(\mathrm{a} ; \mathrm{b}), \mathrm{x}] \rightarrow \operatorname{Col}(\mathrm{F})(\mathrm{x})] \rightarrow \operatorname{Col}(\mathrm{F})[(\mathrm{c} ; \mathrm{d})]
\end{gathered}
$$

Consider, now, the third conjunct of $(*)$ :

$$
\forall \mathrm{x}[\Sigma(\mathrm{R}, \mathrm{Q})[(\mathrm{a} ; \mathrm{b}), \mathrm{x}] \rightarrow \operatorname{Col}(\mathrm{F})(\mathrm{x})]
$$

What we wish to show is that this conjunct follows from:

$$
\forall \mathrm{y} \forall \mathrm{z}[\text { Ray \& Qbz } \rightarrow \text { Fyz] }
$$

We suppose that $\Sigma(\mathrm{R}, \mathrm{Q})[(\mathrm{a} ; \mathrm{b}), \mathrm{x}]$ and must show that $\operatorname{Col}(\mathrm{F})(\mathrm{x})$. Since $\Sigma(\mathrm{R}, \mathrm{Q})[(\mathrm{a} ; \mathrm{b}), \mathrm{x}]$, we have, by the definition of coupling:

$$
\exists \mathrm{y} \exists \mathrm{z} \exists \mathrm{u} \exists \mathrm{v}[(\mathrm{a} ; \mathrm{b})=(\mathrm{u} ; \mathrm{v}) \& \mathrm{x}=(\mathrm{y} ; \mathrm{z}) \& \text { Ruy \& Qvz] }
$$

By the ordered pair axiom, $\mathrm{u}=\mathrm{a}$ and $\mathrm{v}=\mathrm{b}$, so by the laws of identity: $\exists \mathrm{y} \exists \mathrm{z}[\mathrm{x}=(\mathrm{y} ; \mathrm{z}) \&$ Ray \& Qbz]. But, by hypothesis, if Ray \& Qbz, then Fyz; so: $\exists y \exists z[x=(y ; z) \&$ Fyz]. But, therefore, $\operatorname{Col}(F)(x)$, by definition.

Similarly, the second conjunct of $(*)$ follows from:

$$
\forall \mathrm{x} \forall \mathrm{y} \forall \mathrm{z} \forall \mathrm{w}(\text { Fxy \& Rxz \& Qyw } \rightarrow \text { Fzw })
$$

Thus, applying these two results and the definition of ' $\operatorname{Col}(\mathrm{F})(\xi)$ ' to $(*)$, we have:

$\mathscr{F}[\Sigma(\mathrm{R}, \mathrm{Q})][(\mathrm{a} ; \mathrm{b}),(\mathrm{c} ; \mathrm{d})] \& \forall \mathrm{x} \forall \mathrm{y} \forall \mathrm{z} \forall \mathrm{w}(\mathrm{Fxy} \& \mathrm{Rxz} \& \mathrm{Qyw} \rightarrow \mathrm{Fzw}) \&$ 


$$
\forall \mathrm{y} \forall \mathrm{z}[\mathrm{Ray} \& \mathrm{Qbz} \rightarrow \mathrm{Fyz}] \rightarrow \mathrm{Fcd}
$$

This is Frege's Theorem 231, and it is one of the forms of induction he uses in his proof of Theorem 263. Note that all reference to ordered pairs has been eliminated, except in the first conjunct, where it is needed for the application of the ancestral.

Frege is thus using ordered pairs to define a two-place relation, $\Sigma(\mathrm{R}, \mathrm{Q})(\xi, \eta)$, from a four-place relation, $\mathrm{R} \xi \eta \& \mathrm{Q} \zeta \tau$, so that he can use the ancestral and the theorems proven about it (e.g., Theorem 123) to prove results about series determined by such relations. That is to say, just as Frege's definition of ordered pairs is used, essentially, only in the proof of the ordered pair axiom, what is important about ordered pairs is that one can use the ancestral to define series of ordered pairs; and what, in turn, is important about series of ordered pairs is that they satisfy theorems such as Theorem 231, from which reference to ordered pairs has been almost entirely eliminated. It therefore seems natural to abandon the use of ordered pairs entirely and to formulate a definition of the ancestral, for four-place relations, on the model of Frege's Theorem 231.

We thus define the strong 2-ancestral as follows:

$$
\begin{aligned}
\mathscr{F}_{2}(\mathrm{R} \xi, \eta ; \zeta, \tau)(\mathrm{a}, \mathrm{b} ; \mathrm{c}, \mathrm{d}) \equiv \mathrm{df} \\
\quad \forall \mathrm{F}[\forall \mathrm{x} \forall \mathrm{y} \forall \mathrm{z} \forall \mathrm{w}(\mathrm{Fxy} \& \mathrm{Rxyzw} \rightarrow \mathrm{Fzw}) \& \forall \mathrm{y} \forall \mathrm{z}[\mathrm{Rabxy} \rightarrow \mathrm{Fxy}] \rightarrow \text { Fcd }
\end{aligned}
$$

We similarly define the weak 2-ancestral as:

$$
\mathscr{F}={ }_{2}(\mathrm{R} \xi, \eta ; \zeta, \tau)(\mathrm{a}, \mathrm{b} ; \mathrm{c}, \mathrm{d}) \equiv \mathrm{df} \mathscr{F}_{2}(\mathrm{R})(\mathrm{a}, \mathrm{b} ; \mathrm{c}, \mathrm{d}) \vee(\mathrm{a}=\mathrm{c} \& \mathrm{~b}=\mathrm{d})
$$

These definitions are plainly analogous to Frege's definition of the ancestral for two-place relations.

As we shall see, Theorem 263 can be proven using this definition of the 2-ancestral and so without the use of ordered pairs. Of course, if we are to use the 2-ancestral to prove Theorem 263, we must prove the analogues of those theorems about the ancestral which Frege uses in his proof. As an example, consider Frege's Theorem 131:

$$
\mathrm{Qad} \rightarrow \mathscr{F}(\mathrm{Q})(\mathrm{a}, \mathrm{d})
$$

The analogue, for the 2-ancestral, we may call Theorem $131_{2}$ :

$$
\mathrm{Qab} ; \mathrm{cd} \rightarrow \mathscr{F}_{2}(\mathrm{Q})(\mathrm{a}, \mathrm{b} ; \mathrm{c}, \mathrm{d})
$$

To prove this, we use Theorem $127_{2}$, which is immediate from the definition of the 2-ancestral:

$$
\forall \mathrm{F}\{\forall \mathrm{x} \forall \mathrm{y}[\mathrm{Q} a b ; \mathrm{xy} \rightarrow \mathrm{Fxy}] \& \forall \mathrm{x} \forall \mathrm{y} \forall \mathrm{z} \forall \mathrm{w}[\mathrm{Fxy} \& \mathrm{Qxy} ; \mathrm{zw} \rightarrow \mathrm{Fzw}] \rightarrow \mathrm{Fcd}\} \rightarrow
$$




$$
\mathscr{F}_{2}(\mathrm{Q})(\mathrm{a}, \mathrm{b} ; \mathrm{c}, \mathrm{d})
$$

For the proof of $\left(131_{2}\right)$, suppose that $F \xi \eta$ is hereditary in the Q-series and that, if Qab; $x y$, then Fxy; we must show that Fcd. But, by hypothesis, Qab;cd; so Fcd. Done.

This proof of Theorem $131_{2}$ simply mirrors Frege's proof of Theorem 131. Indeed, it will always be possible to prove analogues of Frege's theorems concerning the ancestral by following his proofs of the original theorems, making use of analogues whenever he makes use of a theorem about the ancestral. The reason for this is, of course, that the definition of the 2-ancestral is itself a precise analogue of his definition of the ancestral. To see exactly in what sense this is so, define the $n$-ancestral, on the same model, as follows:

$$
\begin{aligned}
& \mathscr{F}_{\mathrm{n}}\left(\mathrm{R} \xi_{1} \ldots \xi_{\mathrm{n}} ; \eta_{1} \ldots \eta_{\mathrm{n}}\right)\left(\mathrm{a}_{1} \ldots \mathrm{a}_{\mathrm{n}} ; \mathrm{b}_{1} \ldots \mathrm{b}_{\mathrm{n}}\right) \equiv \mathrm{df} \\
& \forall \mathrm{F}\left\{\forall \mathrm{x}_{1} \ldots \forall \mathrm{x}_{\mathrm{n}}\left[\mathrm{R}\left(\mathrm{a}_{1} \ldots \mathrm{a}_{\mathrm{n}} ; \mathrm{x}_{1} \ldots \mathrm{x}_{\mathrm{n}}\right) \rightarrow \mathrm{Fx}_{1} \ldots \mathrm{x}_{\mathrm{n}}\right] \&\right. \\
& \forall \mathrm{x}_{1} \ldots \forall \mathrm{x}_{\mathrm{n}} \forall \mathrm{y}_{1} \ldots \forall \mathrm{y}_{\mathrm{n}}\left[\mathrm{R}\left(\mathrm{x}_{1} \ldots \mathrm{x}_{\mathrm{n}} ; \mathrm{y}_{1} \ldots \mathrm{y}_{\mathrm{n}}\right) \& \mathrm{Fx}_{1} \ldots \mathrm{x}_{\mathrm{n}} \rightarrow \mathrm{Fy}_{1} \ldots \mathrm{y}_{\mathrm{n}}\right] \rightarrow \\
& \left.\mathrm{Fb}_{1} \ldots \mathrm{b}_{\mathrm{n}}\right\}
\end{aligned}
$$

We now write ' $\mathbf{x}$ ' for ' $\mathrm{x}_{1} \ldots \mathrm{x}_{\mathrm{n}}$ ' and ' $\mathbf{x}=\mathbf{y}^{\prime}$ for ' $\mathrm{x}_{1}=\mathrm{y}_{1} \& \ldots \& \mathrm{x}_{\mathrm{n}}=\mathrm{y}_{\mathrm{n}}{ }^{\prime}$; the definition of the $\mathrm{n}$-ancestral can then be written as:

$$
\mathscr{F}_{\mathrm{n}}(\mathrm{R} \xi ; \eta)(\mathbf{a} ; \mathbf{b}) \equiv \mathrm{df} \forall \mathrm{F}[\forall \mathbf{x}(\mathrm{Rax} \rightarrow \mathrm{Fx}) \& \forall \mathbf{x} \forall \mathbf{y}(\mathrm{Rxy} \& \mathrm{Fx} \rightarrow \mathrm{Fy}) \rightarrow \mathrm{Fb}]
$$

And, of course, we define the weak n-ancestral as:

$$
\mathscr{F}_{\mathrm{n}}=(\mathrm{R} \xi ; \eta)(\mathbf{a} ; \mathbf{b}) \equiv \mathrm{df} \mathscr{F}_{\mathrm{n}}(\mathrm{R} \xi ; \eta)(\mathbf{a} ; \mathbf{b}) \vee \mathbf{a}=\mathbf{b}
$$

To say that this definition schema was reminiscent of Frege's definition of the ancestral would be an understatement. It is because of the similarity which this familiar notational trick reveals that Frege's proofs of theorems concerning the ancestral can be immediately transformed into proofs of theorems concerning each of the various n-ancestrals.

Theorem 231, of course, is not an analogue of a theorem concerning the ordinary ancestral, since it makes reference to ordered pairs. Nevertheless, if we employ the definition of coupling introduced above which makes no use of ordered pairs, together with the 2-ancestral, we can formulate a precise analogue of Theorem 231 and prove it essentially as Frege proves Thoerem 231 itself. The proof of the analogue shows it to be a nearly immediate consequence of Theorem $123_{2}$ :

$$
\mathscr{F}_{2}(\mathrm{R} \xi, \eta ; \zeta, \tau)(\mathrm{a}, \mathrm{b} ; \mathrm{c}, \mathrm{d}) \& \forall \mathrm{x} \forall \mathrm{y} \forall \mathrm{z} \forall \mathrm{w}(\mathrm{Fxy} \& \mathrm{Rxyzw} \rightarrow \mathrm{Fzw}) \&
$$




$$
\forall \mathrm{y} \forall \mathrm{z}[\mathrm{Rabxy} \rightarrow \mathrm{Fxy}] \rightarrow \mathrm{Fcd}
$$

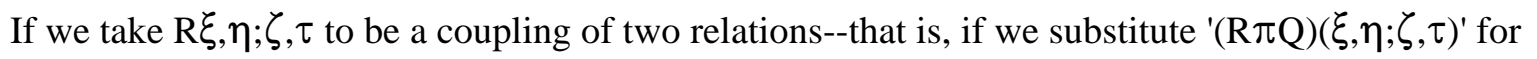
'R $\xi, \eta ; \zeta, \tau '--$ then we have:

$$
\begin{gathered}
\mathscr{F}_{2}[\mathrm{R} \pi \mathrm{Q}](\mathrm{a}, \mathrm{b} ; \mathrm{c}, \mathrm{d}) \& \forall \mathrm{x} \forall \mathrm{y} \forall \mathrm{z} \forall \mathrm{w}(\mathrm{Fxy} \&(\mathrm{R} \pi \mathrm{Q})(\mathrm{x}, \mathrm{y} ; \mathrm{z}, \mathrm{w}) \rightarrow \mathrm{Fzw}) \& \\
\forall \mathrm{y} \forall \mathrm{z}[(\mathrm{R} \pi \mathrm{Q})(\mathrm{a}, \mathrm{b} ; \mathrm{x}, \mathrm{y}) \rightarrow \mathrm{Fxy}] \rightarrow \mathrm{Fcd}
\end{gathered}
$$

As above, we have, by the definition of coupling:

$$
\begin{gathered}
\mathscr{F}_{2}[\mathrm{R} \pi \mathrm{Q}](\mathrm{a}, \mathrm{b} ; \mathrm{c}, \mathrm{d}) \& \forall \mathrm{x} \forall \mathrm{y} \forall \mathrm{z} \forall \mathrm{w}(\mathrm{Fxy} \& \mathrm{Rxz} \& \text { Qyw } \rightarrow \text { Fzw }) \& \\
\forall \mathrm{y} \forall \mathrm{z}[\mathrm{Rax} \& \text { \&by } \rightarrow \text { Fxy }] \rightarrow \text { Fcd }
\end{gathered}
$$

This is the mentioned analogue of Frege's Theorem 231.

It seems to me that Frege almost certainly knew that his uses of ordered pairs were inessential to his proof. He uses a number of other forms of induction, for series determined by the couplings of relations. In each of these cases (e.g., Theorem 257), reference to ordered pairs is similarly eliminated from the theorem, except in terms in which the ancestral itself occurs. Surely, it would have been obvious to Frege that the use of ordered pairs was unnecessary, if not at the outset, then at least by reflection on the pattern which these theorems display, namely, the pattern used above to motivate the definition of the 2-ancestral. For this reason, I shall reproduce Frege's proof of Theorem 263 using the definition of the 2ancestral, rather than ordered pairs. One might wonder, however, why, if Frege knew he could do without ordered pairs, he made use of them. One can only speculate about such a question, but the following two part answer has some plausibility: Firstly, ordered pairs were in wide use in mathematics, no suitable definition of them had at that time (1893) been given, and the provision of such a definition contributes to Frege's claim to be able to formalize, in the language of Grundgesetze, all of mathematics. Secondly, using ordered pairs in this context relieves Frege both of having to introduce a new definition of the ancestral and of having to prove a number of theorems which are simple analogues of ones he had already proven. More generally, the use of ordered pairs unifies the treatment of the 2-ancestral and the usual ancestral (not to mention the various other n-ancestrals). The use of ordered pairs thus has not insignificant advantages: If one can define them, why not use them?

We, however, are not in the same position Frege was. To use ordered pairs in the proof of Theorem 263, we should have to add the ordered pair axiom to Fregean Arithmetic: So far as I know, 
ordered pairs are not definable in FA. Indeed, it is an interesting and open question whether FA plus the ordered pair axiom is even a conservative extension of FA. ${ }^{17}$

\section{Definition by Induction}

We now return to the proof of Theorem 263. I shall discuss only parts of Frege's proof here, namely, those parts which are of some conceptual interest. Those parts of the proof which proceed primarily by brute force (i.e., by repeated applications of the ancestral) will be omitted.

Recall that Theorem 263 is:

$\exists \mathrm{Q}[\operatorname{Func}(\mathrm{Q}) \& \neg \exists \mathrm{x} . \mathscr{F}(\mathrm{Q})(\mathrm{x}, \mathrm{x}) \& \forall \mathrm{x}(\neg \exists \mathrm{y} . \mathrm{Qx}, \mathrm{y} \rightarrow \neg \mathrm{Gx}) \& \exists \mathrm{x} \forall \mathrm{y}(\mathrm{Gy} \equiv \mathscr{F}=(\mathrm{Q})(\mathrm{x}, \mathrm{y}))] \rightarrow$ $\mathrm{Nx}: \mathrm{Gx}=\infty$

The Theorem follows immediately from Frege's Theorem 262, which is:

$$
\operatorname{Func}(\mathrm{Q}) \& \neg \exists \mathrm{x} \cdot \mathscr{F}(\mathrm{Q})(\mathrm{x}, \mathrm{x}) \& \forall \mathrm{x}[\mathscr{F}=(\mathrm{Q})(\mathrm{a}, \mathrm{x}) \rightarrow \exists \mathrm{y} \cdot \mathrm{Qxy}] \rightarrow \mathrm{Nx}: \mathscr{F}=(\mathrm{Q})(\mathrm{a}, \mathrm{x})=\infty
$$

Two pieces of terminology. If $\mathrm{Q} \xi \eta$ is functional and no object follows after itself in the Q-series, let us say that the Q-series is simple. If every member of the Q-series beginning with a stands in the Q-relation to some object, let us say that the Q-series beginning with a is endless. Theorem 262 thus says that, if the Q-series is simple and if the Q-series beginning with a is endless, then the number of members of the Qseries beginning with a is Endlos.--Theorem 263 then follows, since the number of Gs is certainly Endlos if the Gs are the members of the Q-series beginning with a.

Hence, the Theorem follows from the definition of Endlos and Frege's Theorem 262, ๆ:

$$
\begin{gathered}
\text { Func }(\mathrm{Q}) \& \neg \exists \mathrm{x} \cdot \mathscr{F}(\mathrm{Q})(\mathrm{x}, \mathrm{x}) \& \forall \mathrm{x}[\mathscr{F}=(\mathrm{Q})(\mathrm{a}, \mathrm{x}) \rightarrow \exists \mathrm{y} \cdot \mathrm{Qxy}] \rightarrow \\
\mathrm{Nx}: \mathscr{F}=(\mathrm{Q})(\mathrm{a}, \mathrm{x})=\mathrm{Nx}: \mathscr{F}=(\text { Pred })(0, \mathrm{x})
\end{gathered}
$$

This Theorem is to be proven, as Frege indicates in the remarks quoted above, by showing that, if the antecedent holds, then there is a relation which maps the natural numbers into the members of the Qseries beginning with a and whose converse maps the latter concept into the former. Recall that $(\mathrm{R} \pi \mathrm{Q})(\xi, \eta)$ is the coupling of the relations $\mathrm{R} \xi \eta$ and $\mathrm{Q} \xi \eta$, which is defined as:

$$
(\mathrm{R} \pi \mathrm{Q})(\mathrm{a}, \mathrm{b} ; \mathrm{c}, \mathrm{d}) \equiv \mathrm{df} \mathrm{Rac} \& \mathrm{Qbd}
$$

The mapping relation is then to be:

$$
\mathscr{F}_{2}=[\operatorname{Pred} \pi \mathrm{Q}](0, \mathrm{a} ; \xi, \eta)
$$


Because relations defined in this way are of such importance in this connection, Frege introduces an abbreviation, which we reproduce as (see $G g$ I §144):

$$
\mathscr{F} \wedge_{\alpha \in \gamma \delta}[\mathrm{R}(\alpha, \epsilon ; \gamma, \delta) ; \mathrm{b}, \mathrm{c}](\mathrm{x}, \mathrm{y}) \equiv \mathrm{df} \mathscr{F}_{2}{ }^{=}(\mathrm{R})(\mathrm{b}, \mathrm{c} ; \mathrm{x}, \mathrm{y})
$$

Thus, an object $\mathrm{x}$ stands in the $\mathscr{F}^{\wedge}(\mathrm{R} ; \mathrm{b}, \mathrm{c})(\xi, \eta)$-relation to y just in case the pair of $\mathrm{x}$ and $\mathrm{y}$ follows after the pair of $\mathrm{b}$ and $\mathrm{c}$ in the R-series. The relation which correlates the natural numbers one-to-one with the members of the Q-series beginning with a is thus to be: $\mathscr{F}^{\wedge}[(\operatorname{Pred} \pi \mathrm{Q}) ; 0, \mathrm{a}](\xi, \eta)$.

We turn, then, to the proof of Theorem 262, $\eta$, which is, again:

$$
\begin{gathered}
\text { Func }(\mathrm{Q}) \& \neg \exists \mathrm{x} \cdot \mathscr{F}(\mathrm{Q})(\mathrm{x}, \mathrm{x}) \& \forall \mathrm{x}[\mathscr{F}=(\mathrm{Q})(\mathrm{a}, \mathrm{x}) \rightarrow \exists \mathrm{y} \cdot \mathrm{Qxy}] \rightarrow \\
\mathrm{Nx}: \mathscr{F}=(\mathrm{Q})(\mathrm{a}, \mathrm{x})=\mathrm{Nx}: \mathscr{F}=(\text { Pred })(0, \mathrm{x})
\end{gathered}
$$

Frege's proof of this Theorem requires three lemmas, the first of which is Theorem 254:

$$
\begin{gathered}
\operatorname{Func}(\mathrm{R}) \& \operatorname{Func}(\mathrm{Q}) \& \neg \exists \mathrm{y}\left(\mathscr{F}^{=}(\mathrm{R})(\mathrm{m}, \mathrm{y}) \& \mathscr{F}(\mathrm{R})(\mathrm{y}, \mathrm{y})\right) \& \forall \mathrm{x}\left[\mathscr{F}^{=}(\mathrm{Q})(\mathrm{a}, \mathrm{x}) \rightarrow \exists \mathrm{y} \cdot \mathrm{Qxy}\right] \rightarrow \\
\operatorname{Map}\left[\mathscr{F}^{\wedge}(\mathrm{R} \pi \mathrm{Q} ; \mathrm{m}, \mathrm{a})\right]\left(\mathscr{F}^{=}(\mathrm{R})(\mathrm{m}, \xi), \mathscr{F}^{=}(\mathrm{Q})(\mathrm{a}, \xi)\right)
\end{gathered}
$$

Another piece of terminology. If $\mathrm{R} \xi \eta$ is functional and no member of the $\mathrm{R}$-series beginning with $\mathrm{m}$ follows after itself, then we say that the R-series beginning with $m$ is simple. Thus, Theorem 254 says that, if the R-series beginning with $\mathrm{m}$ is simple, and if $\mathrm{Q} \xi \eta$ is functional and the $\mathrm{Q}$-series beginning with a is endless, then $\mathscr{F}^{\wedge}(\mathrm{R} \pi \mathrm{Q} ; \mathrm{m}, \mathrm{a})(\xi, \eta)$ maps the members of the R-series beginning with $\mathrm{m}$ into the members of the Q-series beginning with a. The second lemma is Theorem 256:

$$
\begin{aligned}
& \text { Func }(\mathrm{Q}) \& \forall \mathrm{y}\left(\mathscr{F}^{=}(\mathrm{Q})(\mathrm{a}, \mathrm{y}) \rightarrow \exists \mathrm{z} \cdot \mathrm{Qyz}\right) \rightarrow \\
& \operatorname{Map}\left[\mathscr{F}^{\wedge}(\text { Pred } \pi \mathrm{Q} ; 0, \mathrm{a})\right]\left(\mathscr{F}^{=}(\text {Pred })(0, \xi), \mathscr{F}^{=}(\mathrm{Q})(\mathrm{a}, \xi)\right)
\end{aligned}
$$

That is: If $\mathrm{Q} \xi \eta$ is functional and the Q-series beginning with a is endless, then $\mathscr{F}^{\wedge}(\operatorname{Pred} \pi \mathrm{Q} ; 0, \mathrm{a})(\xi, \eta)$ maps the natural numbers into the members of the Q-series beginning with a. The third, and last, lemma is Theorem 259:

$$
\forall \mathrm{y} \forall \mathrm{z}\left\{\mathscr{F}^{\wedge}(\mathrm{Q} \pi \mathrm{R} ; \mathrm{a}, \mathrm{m})(\mathrm{y}, \mathrm{z}) \equiv \operatorname{Conv}\left[\mathscr{F}^{\wedge}(\mathrm{R} \pi \mathrm{Q} ; \mathrm{m}, \mathrm{a})\right](\mathrm{y}, \mathrm{z})\right\}
$$

That is: $\mathscr{F}^{\wedge}(\mathrm{Q} \pi \mathrm{R} ; \mathrm{a}, \mathrm{m})(\xi, \eta)$ is the converse of $\mathscr{F}^{\wedge}(\mathrm{R} \pi \mathrm{Q} ; \mathrm{m}, \mathrm{a})(\xi, \eta)$.

To prove Theorem 262, $\eta$, we assume the antecedent and show that $\mathscr{F}^{\wedge}[\operatorname{Pred} \pi \mathrm{Q} ; 0, \mathrm{a}](\xi, \eta)$ correlates the natural numbers one-to-one with the members of the Q-series beginning with a. Now, $\mathrm{Q} \xi \eta$ is functional and the Q-series beginning with a is endless. So, $\mathscr{F}^{\wedge}(\operatorname{Pred} \pi \mathrm{Q} ; 0, \mathrm{a})(\xi, \eta)$ maps the natural 
numbers into the members of the Q-series beginning with a, by Theorem 256. Moreover, if, in Theorem 254, we take $\mathrm{Q} \xi \eta$ as $\operatorname{Pred}(\xi, \eta), \mathrm{R} \xi \eta$ as $\mathrm{Q} \xi \eta, \mathrm{m}$ as a, and a as 0 , then we have:

Func $(\mathrm{Q}) \&$ Func(Pred) \& $\neg \exists \mathrm{y}\left(\mathscr{F}^{=}(\mathrm{Q})(\mathrm{a}, \mathrm{y}) \& \mathscr{F}(\mathrm{Q})(\mathrm{y}, \mathrm{y})\right) \&$

$$
\begin{aligned}
& \forall \mathrm{y}\left(\mathscr{T}^{=}(\operatorname{Pred})(0, \mathrm{y}) \rightarrow \exists \mathrm{z} \cdot \operatorname{Pred}(\mathrm{y}, \mathrm{z})\right) \rightarrow \\
& \operatorname{Map}\left[\mathscr{F}^{\wedge}(\mathrm{Q} \pi \operatorname{Pred} ; \mathrm{a}, 0)\right]\left(\mathscr{F}^{=}(\mathrm{Q})(\mathrm{a}, \xi), \mathscr{F}^{=}(\operatorname{Pred})(0, \xi)\right)
\end{aligned}
$$

The antecedent holds, since, by hypothesis, $\mathrm{Q} \xi \eta$ is functional and no object follows after itself in the Qseries (a fortiori, no member of the Q-series beginning with a does); moreover, $\operatorname{Pred}(\xi, \eta)$ is functional (Frege's Theorem 71) and every natural number is immediately succeeded by a natural number (Frege's Theorem 156); hence, $\mathscr{F}^{\wedge}(\mathrm{Q} \pi$ Pred; a,0)( $\xi, \eta)$ maps the members of the Q-series beginning with a into the natural numbers. Since, by Theorem 259, this relation is the converse of the relation $\mathscr{F}^{\wedge}$ (Pred $\pi \mathrm{Q}$; $0, a)(\xi, \eta)$, the relation $\mathscr{F}^{\wedge}($ Pred $\pi \mathrm{Q} ; 0, \mathrm{a})(\xi, \eta)$ maps the natural numbers into the members of the Qseries beginning with a and its converse maps the latter into the former. Done.

Most of the interest of Frege's proof of Theorem 263 lies in these three lemmas. Recall that Theorem 256 is:

$$
\begin{aligned}
& \text { Func }(\mathrm{Q}) \& \forall \mathrm{x}\left[\mathscr{F}^{=}(\mathrm{Q})(\mathrm{a}, \mathrm{x}) \rightarrow \exists \mathrm{y} \cdot \mathrm{Qxy}\right] \rightarrow \\
& \quad \operatorname{Map}\left[\mathscr{F}^{\wedge}(\text { Pred } \pi \mathrm{Q} ; 0, \mathrm{a})\right]\left(\mathscr{F}^{=}(\text {Pred })(0, \xi), \mathscr{F}^{=}(\mathrm{Q})(\mathrm{a}, \xi)\right)
\end{aligned}
$$

It is this theorem which justifies the definition of a function(al relation), defined on the natural numbers, by induction. For, eliminating 'Map' via the definition, we have:

$$
\begin{aligned}
& \text { Func }(\mathrm{Q}) \& \forall \mathrm{x}\left[\mathscr{F}^{=}(\mathrm{Q})(\mathrm{a}, \mathrm{x}) \rightarrow \exists \mathrm{y} \cdot \mathrm{Qxy}\right] \\
& \rightarrow\left\{\mathrm { x } \left[\mathscr { F } ^ { = } ( \operatorname { P r e d } ) ( 0 , \mathrm { x } ) \rightarrow \exists \mathrm { y } \left\{\mathscr{F}^{=}(\mathrm{Q})\left(\mathscr{F}^{\wedge}(\operatorname{a}, \mathrm{y}) \& \mathscr{F}^{\wedge}(\operatorname{Pred} \pi \mathrm{Q} ; 0, \mathrm{a})\right) \&\right.\right.\right. \\
&\mathrm{Q} ; 0, \mathrm{a})(\mathrm{x}, \mathrm{y})\}]\}
\end{aligned}
$$

If $\mathrm{Q} \xi \eta$ is functional and the Q-series beginning with a is endless, then $\mathscr{F}^{\wedge}(\operatorname{Pred} \pi \mathrm{Q} ; 0, \mathrm{a})(\xi, \eta)$ is functional and every natural number is in its domain. Moreover, it is not difficult to see that its range consists entirely of members of the Q-series beginning with a. ${ }^{18}$

Theorem 256 is thus a version of what is known as the recursion theorem for $\omega$. The usual settheoretic statement of this theorem is:

Let $\mathrm{g}(\xi)$ be a function, $\mathrm{g}: \mathrm{A} \rightarrow \mathrm{A}$; let $\mathrm{a} \in \mathrm{A}$. Then there is a unique function $\varphi: \mathbb{N} \rightarrow \mathrm{A}$ such that $\varphi(0)=a$ and $\varphi(n+1)=g(\varphi(n))$. 
Assume the antecedent and define $\mathrm{Q} \xi \eta \equiv[\eta=\mathrm{g}(\xi)] . \mathrm{Q} \xi \eta$ is then functional, since $\mathrm{g}(\xi)$ is a function, and the Q-series beginning with a is endless, as can easily be seen. Thus, the antecedent of Theorem 256 is satisfied, so $\mathscr{F}^{\wedge}($ Pred $\pi \mathrm{Q} ; 0, \mathrm{a})(\xi, \eta)$ is functional and its domain contains all the natural numbers. Uniqueness is obvious.

It is not hard to see that this relation satisfies the recursion equations. We must show that $\mathscr{F}^{\wedge}(\operatorname{Pred} \pi \mathrm{Q} ; 0, \mathrm{a})(0, \mathrm{a})$, that is, that $\varphi(0)=\mathrm{a}$. And, we must show that $\mathscr{F}^{\wedge}(\operatorname{Pred} \pi \mathrm{Q} ; 0, \mathrm{a})(\mathrm{n}+1, \mathrm{~g}(\mathrm{x}))$, if $\mathscr{F}^{\wedge}(\operatorname{Pred} \pi \mathrm{Q} ; 0, \mathrm{a})(\mathrm{n}, \mathrm{x})$, that is, that $\varphi(\mathrm{n}+1)=\mathrm{g}(\varphi(\mathrm{n}))$. But, by definition, $\mathscr{F}^{\wedge}(\operatorname{Pred} \pi \mathrm{Q} ; 0, \mathrm{a})(0, \mathrm{a})$ if, and only if, $\mathscr{F}=($ Pred $\pi \mathrm{Q})(0, \mathrm{a} ; 0, \mathrm{a})$, which follows from Theorem $140_{2} \cdot{ }^{19}$ Suppose, then, that $\mathscr{F}^{\wedge}(\operatorname{Pred} \pi \mathrm{Q} ; 0, \mathrm{a})(\mathrm{n}, \mathrm{x})$. Then, by definition, $\mathscr{F}=(\operatorname{Pred} \pi \mathrm{Q})(0, \mathrm{a} ; \mathrm{n}, \mathrm{x})$; furthermore, Pred $(\mathrm{n}, \mathrm{n}+1)$ and $\mathrm{Qx}, \mathrm{g}(\mathrm{x})$, this last by the definition of $\mathrm{Q} \xi \eta$; hence, (Pred $\pi \mathrm{Q})(\mathrm{n}, \mathrm{x} ; \mathrm{n}+1, \mathrm{~g}(\mathrm{x}))$, by the definition of coupling. We have, then, Theorem $137_{2}$ :

$$
\mathscr{F}_{2}=(\mathrm{R})(\mathrm{b}, \mathrm{c} ; \mathrm{y}, \mathrm{z}) \& \mathrm{Ryz} ; \mathrm{uv} \rightarrow \mathscr{F}_{2}{ }^{=}(\mathrm{R})(\mathrm{b}, \mathrm{c} ; \mathrm{u}, \mathrm{v})
$$

Since $\mathscr{F}^{=}(\operatorname{Pred} \pi \mathrm{Q})(0, \mathrm{a} ; \mathrm{n}, \mathrm{x})$ and $(\operatorname{Pred} \pi \mathrm{Q})(\mathrm{n}, \mathrm{x} ; \mathrm{n}+1, \mathrm{~g}(\mathrm{x}))$, we have that $\mathscr{F}=(\operatorname{Pred} \pi \mathrm{Q})(0, \mathrm{a} ; \mathrm{n}+1, \mathrm{~g}(\mathrm{x}))$; hence, $\mathscr{F}^{\wedge}($ Pred $\pi \mathrm{Q} ; 0, \mathrm{a})(\mathrm{n}+1, \mathrm{~g}(\mathrm{x}))$, by definition.

As an example, consider the recursion equations: ${ }^{20}$

$$
\begin{aligned}
& \varphi(0)=\mathrm{a} \\
& \varphi(\mathrm{Sm})=\mathrm{S}(\varphi(\mathrm{m}))
\end{aligned}
$$

( $\mathrm{S} \xi$ here is the successor-function.) As above, we define $\mathrm{Q} \xi \eta$ as $\eta=\mathrm{S} \xi$; thus, $\mathrm{Q} \xi \eta$ is just $\operatorname{Pred}(\xi, \eta)$. Hence, by the above, $\mathscr{F}^{\wedge}[$ Pred $\pi$ Pred; $0, a](\xi ; \eta)$ is functional and satisfies these equations. We may write them, in more familiar form, as:

$$
\begin{aligned}
& a+0=a \\
& a+S m=S(a+m)
\end{aligned}
$$

These are, of course, the standard recursion equations for addition. Thus, $\mathscr{F}^{\wedge}[\operatorname{Pred} \pi$ Pred; $0, \mathrm{a}](\xi ; \eta)$ holds just in case $\eta=\mathrm{a}+\xi$; so

$$
\mathscr{F}^{\wedge}[(\text { Pred } \pi \text { Pred }) ; 0, \zeta](\xi ; \eta)
$$

defines $\eta=\zeta+\xi$, for natural numbers. ${ }^{21}$ 
Frege's proof of Theorem 256 can be carried out in Fregean Arithmetic. The general theorem licensing the definition of a function by induction is, however, Theorem 254, from which Theorem 256 easily follows. Substituting 'Pred $(\xi, \eta)$ ' for ' $R \xi \eta$ ' and '0' for 'm' in (254), we have:

Func(Pred) \& Func $(\mathrm{Q}) \& \forall \mathrm{x}\left[\mathscr{F}^{=}(\mathrm{Q})(\mathrm{a}, \mathrm{x}) \rightarrow \exists \mathrm{y} . \mathrm{Qxy}\right] \&$

$$
\begin{aligned}
& \neg \exists \mathrm{y}\left(\mathscr{F}^{=}(\text {Pred })(0, \mathrm{y}) \& \mathscr{F}(\text { Pred })(\mathrm{y}, \mathrm{y})\right) \rightarrow \\
& \operatorname{Map}\left(\mathscr{F}^{\wedge}(\text { Pred } \pi \mathrm{Q} ; 0, \mathrm{x})\right)\left(\mathscr{F}^{=}(\text {Pred })(0, \xi), \mathscr{F}^{=}(\mathrm{Q})(\mathrm{x}, \xi)\right)
\end{aligned}
$$

$\operatorname{But} \operatorname{Pred}(\xi, \eta)$ is provably functional, and no natural number follows after itself in the Pred-series, by Frege's Theorem 255 (which follows easily from Frege's Theorem 145). Theorem 256 follows immediately.

The validity of the definition of a function on the natural numbers, by induction, thus follows from Theorem 254, the functionality of $\operatorname{Pred}(\xi, \eta)$, and the fact that no finite number follows after itself in the Pred-series: Note that the endlessness (infinity) of the series of natural numbers is not needed for the proof of Theorem 256. Theorem 254 itself states that, if $\mathrm{R} \xi \eta$ is functional and no member of the $\mathrm{R}$ series beginning with $\mathrm{m}$ follows after itself in the R-series, then, if $\mathrm{Q} \xi \eta$ is functional and the Q-series beginning with a is endless, $\mathscr{F}^{\wedge}(\mathrm{R} \pi \mathrm{Q} ; \mathrm{m}, \mathrm{a})(\xi, \eta)$ is a functional relation whose domain contains the whole of the R-series beginning with $\mathrm{m}$ : Thus, Theorem 254 justifies the definition of a functional relation, by induction, on any "unbranching" series which does not "turn back on itself"; it is for this reason that I referred to it earlier as the general theorem licensing definition by induction. What is remarkable about Theorem 254 is that it is itself a theorem of second-order logic: The general theory of definition by induction can be developed entirely within second-order logic, and it was Frege who first showed that it can be (modulo his use of ordered pairs).

It is worth proving Theorem 262, $\eta$, and so Theorem 263, from the lemmas, in a slightly different way, to see just what Frege has done here. First, we exchange 'R $\xi \eta$ ' with 'Q $\xi \eta$ ', and 'm' with 'a', in Theorem 254, yielding:

$$
\begin{gathered}
\text { Func }(\mathrm{R}) \& \operatorname{Func}(\mathrm{Q}) \& \neg \exists \mathrm{y}\left(\mathscr{F}^{=}(\mathrm{Q})(\mathrm{a}, \mathrm{y}) \& \mathscr{F}(\mathrm{Q})(\mathrm{y}, \mathrm{y})\right) \& \forall \mathrm{y}\left(\mathscr{F}^{=}(\mathrm{R})(\mathrm{m}, \mathrm{y}) \rightarrow \exists \mathrm{z} \cdot \mathrm{Ryz}\right) \rightarrow \\
\operatorname{Map}\left[\mathscr{F}^{\wedge}(\mathrm{Q} \pi \mathrm{R} ; \mathrm{a}, \mathrm{m})\right]\left(\mathscr{F}^{=}(\mathrm{Q})(\mathrm{a}, \xi), \mathscr{F}^{=}(\mathrm{R})(\mathrm{m}, \xi)\right)
\end{gathered}
$$

By Theorem 259, then:

$$
\operatorname{Func}(\mathrm{R}) \& \operatorname{Func}(\mathrm{Q}) \& \neg \exists \mathrm{y}\left(\mathscr{F}^{=}(\mathrm{Q})(\mathrm{a}, \mathrm{y}) \& \mathscr{F}(\mathrm{Q})(\mathrm{y}, \mathrm{y})\right) \& \forall \mathrm{y}\left(\mathscr{F}^{=}(\mathrm{R})(\mathrm{m}, \mathrm{y}) \rightarrow \exists \mathrm{z} \cdot \mathrm{Ryz}\right) \rightarrow
$$




$$
\operatorname{Map}\left[\operatorname{Conv}\left[\mathscr{F}^{\wedge}(\mathrm{R} \pi \mathrm{Q} ; \mathrm{m}, \mathrm{a})\right]\right]\left(\mathscr{T}^{=}(\mathrm{Q})(\mathrm{a}, \xi), \mathscr{F}^{=}(\mathrm{R})(\mathrm{m}, \xi)\right)
$$

Putting this together with Theorem 254, we have:

$$
\begin{gathered}
\text { Func }(\mathrm{Q}) \& \neg \exists \mathrm{y}\left(\mathscr{F}^{=}(\mathrm{Q})(\mathrm{a}, \mathrm{y}) \& \mathscr{F}(\mathrm{Q})(\mathrm{y}, \mathrm{y})\right) \& \forall \mathrm{y}\left(\mathscr{F}^{=}(\mathrm{Q})(\mathrm{a}, \mathrm{y}) \rightarrow \exists \mathrm{z} \cdot \mathrm{Qyz}\right) \& \\
\text { Func }(\mathrm{R}) \& \neg \exists \mathrm{y}\left(\mathscr{F}^{=}(\mathrm{R})(\mathrm{m}, \mathrm{y}) \& \mathscr{F}(\mathrm{R})(\mathrm{y}, \mathrm{y})\right) \& \forall \mathrm{y}(\mathscr{F}=(\mathrm{R})(\mathrm{m}, \mathrm{y}) \rightarrow \exists \mathrm{z} . \mathrm{Ryz}) \rightarrow \\
\operatorname{Map}\left(\mathscr{F}^{\wedge}(\mathrm{R} \pi \mathrm{Q} ; \mathrm{m}, \mathrm{a})\right)\left(\mathscr{F}=(\mathrm{R})(\mathrm{m}, \xi), \mathscr{F}^{=}(\mathrm{Q})(\mathrm{a}, \xi)\right) \& \\
\operatorname{Map}\left[\operatorname{Conv}\left(\mathscr{F}^{\wedge}(\mathrm{R} \pi \mathrm{Q} ; \mathrm{m}, \mathrm{a})\right)\right]\left(\mathscr{F}^{=}(\mathrm{Q})(\mathrm{a}, \xi), \mathscr{F}^{=}(\mathrm{R})(\mathrm{m}, \xi)\right)
\end{gathered}
$$

This result, which we may call the Isomporphism Theorem, thus says that, if the R-series beginning with $\mathrm{m}$ and the Q-series beginning with a both are simple and endless (or, simply endless),

$\mathscr{T}^{\wedge}(\mathrm{R} \pi \mathrm{Q} ; \mathrm{m}, \mathrm{a})(\xi, \eta)$ maps the former series into the latter and its converse maps the latter series into the former. Since, as it is not particularly difficult to see, these relations are order-preserving--where the ordering relations are the strong ancestrals of $\mathrm{R} \xi \eta$ and $\mathrm{Q} \xi \eta$--this theorem implies that all simply endless series are isomorphic. ${ }^{22}$ Hence the name.

Theorem $262, \eta$ then follows by substituting 'Pred $(\xi, \eta)$ ' for ' $R \xi \eta$ ', and ' 0 ', for ' $m$ ', and noting that the Pred-series beginning with 0 is simply endless. Frege thus in effect proceeds by first proving that all simply endless series are isomorphic and then concluding that, since the series of natural numbers is a simply endless series, every simply endless series is isomorphic to (and hence equinumerous with) it. The Isomorphism Theorem is an immediate and trivial consequence of Frege's Theorems 254 and 259, and these two Theorems are, as has been said, theorems of second-order logic. The Isomorphism Theorem is thus itself a theorem of second-order logic, and Frege's proof in effect shows it so to be. Facts about the natural numbers, derived from Hume's Principle, are used only in the derivation of Theorem 256 from Theorem 254 and of Theorem 263 from the Isomorphism Theorem. 


\section{The Definition of Relations by Induction}

We now turn to the proof of the central lemma in Frege's proof of Theorem 263, Theorem 254. (The proof of Theorem 259 is not difficult and will be omitted.) Recall that Theorem 254 is:

$\operatorname{Func}(\mathrm{R}) \& \operatorname{Func}(\mathrm{Q}) \& \neg \exists \mathrm{y}\left[\mathscr{F}^{=}(\mathrm{R})(\mathrm{m}, \mathrm{y}) \& \mathscr{F}(\mathrm{R})(\mathrm{y}, \mathrm{y})\right] \& \forall \mathrm{y}\left(\mathscr{F}^{=}(\mathrm{Q})(\mathrm{a}, \mathrm{y}) \rightarrow \exists \mathrm{z} \cdot \mathrm{Qyz}\right) \rightarrow$ $\operatorname{Map}\left(\mathscr{F}^{\wedge}(\mathrm{R} \pi \mathrm{Q} ; \mathrm{m}, \mathrm{a})\right)\left(\mathscr{F}^{=}(\mathrm{R})(\mathrm{m}, \xi), \mathscr{F}^{=}(\mathrm{Q})(\mathrm{a}, \xi)\right)$

Theorem 254 is derived from two lemmas, the first of which is Theorem 253:

$\operatorname{Func}(\mathrm{R}) \& \operatorname{Func}(\mathrm{Q}) \& \neg \exists \mathrm{y}\left[\mathscr{F}^{=}(\mathrm{R})(\mathrm{m}, \mathrm{y}) \& \mathscr{F}(\mathrm{R})(\mathrm{y}, \mathrm{y})\right] \rightarrow \operatorname{Func}\left(\mathscr{F}^{\wedge}[\mathrm{R} \pi \mathrm{Q} ; \mathrm{m}, \mathrm{a}]\right)$

That is: If $\mathrm{R} \xi \eta$ and $\mathrm{Q} \xi \eta$ are functional and if no member of the R-series beginning with $\mathrm{m}$ follows after itself in the R-series, then $\mathscr{F}^{\wedge}[(\mathrm{R} \pi \mathrm{Q}) ; \mathrm{m}, \mathrm{a}](\xi, \eta)$ is functional. The second needed lemma is Theorem 241:

$$
\begin{gathered}
\text { Func }\left[\mathscr{F}^{\wedge}(\mathrm{R} \pi \mathrm{Q} ; \mathrm{m}, \mathrm{a})\right] \& \forall \mathrm{y}\left(\mathscr{F}^{=}(\mathrm{Q})(\mathrm{a}, \mathrm{y}) \rightarrow \exists \mathrm{z} . \mathrm{Qyz}\right) \rightarrow \\
\operatorname{Map}\left(\mathscr{F}^{\wedge}[\mathrm{R} \pi \mathrm{Q} ; \mathrm{m}, \mathrm{a}]\right)\left(\mathscr{F}^{=}(\mathrm{R})(\mathrm{m}, \xi), \mathscr{F}^{=}(\mathrm{Q})(\mathrm{a}, \xi)\right)
\end{gathered}
$$

That is: If $\mathscr{F}^{\wedge}(\mathrm{R} \pi \mathrm{Q} ; \mathrm{m}, \mathrm{a})(\xi, \eta)$ is functional and the Q-series beginning with a is endless, then $\mathscr{F}^{\wedge}(\mathrm{R} \pi \mathrm{Q} ; \mathrm{m}, \mathrm{a})(\xi, \eta)$ maps the R-series beginning with $\mathrm{m}$ into the Q-series beginning with a. Theorem 254 is an easy consequence of these two lemmas.

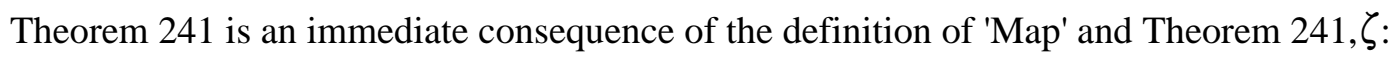

$$
\begin{aligned}
& \forall \mathrm{x}\left[\mathscr{F}^{=}(\mathrm{Q})(\mathrm{a}, \mathrm{x}) \rightarrow \exists \mathrm{y} . \mathrm{Qxy}\right] \rightarrow \forall \mathrm{x}\left\{\mathscr { F } ^ { = } ( \mathrm { R } ) ( \mathrm { m } , \mathrm { x } ) \rightarrow \exists \mathrm { y } \left[\mathscr{F}^{\wedge}(\mathrm{R} \pi \mathrm{Q} ; \mathrm{m}, \mathrm{a})(\mathrm{x}, \mathrm{y}) \&\right.\right. \\
& \left.\left.\mathscr{F}^{=}(\mathrm{Q})(\mathrm{a}, \mathrm{y})\right]\right\}
\end{aligned}
$$

For the consequent states that, if $\mathrm{x}$ belongs to the R-series beginning with $\mathrm{m}$, then $\mathrm{x}$ stands in the $\mathscr{F}^{\wedge}(\mathrm{R} \pi \mathrm{Q} ; \mathrm{m}, \mathrm{a})(\xi, \eta)$-relation to some member of the Q-series beginning with a; hence, by definition, if

$\mathscr{F}^{\wedge}(\mathrm{R} \pi \mathrm{Q} ; \mathrm{m}, \mathrm{a})(\xi, \eta)$ is functional, it maps the R-series beginning with $\mathrm{m}$ into the $\mathrm{Q}$-series beginning with a. Thus: If the Q-series beginning with a is endless, the domain of $\mathscr{T}^{\wedge}(\mathrm{R} \pi \mathrm{Q} ; \mathrm{m}, \mathrm{a})(\xi, \eta)$ contains the whole of the R-series beginning with $m$. Now, Frege's Theorem 232 is:

$$
\mathscr{F}(\mathrm{R} \pi \mathrm{Q})(\mathrm{m}, \mathrm{a} ; \mathrm{x}, \mathrm{y}) \rightarrow[\mathscr{F}(\mathrm{R})(\mathrm{m}, \mathrm{x}) \& \mathscr{F}(\mathrm{Q})(\mathrm{a}, \mathrm{y})]
$$

It follows easily from this theorem that all and only members of the R-series beginning with $\mathrm{m}$ are in the domain and that the range contains only members of the Q-series beginning with a. Thus, the proof of the Theorem 241, $\zeta$ amounts to a proof of the validity of the definition, not of a function, but of a relation, by induction, on the members of the R-series beginning with $\mathrm{m}$, so long as the Q-series beginning with a not 
end. ${ }^{23}$ Frege thus derives the validity of the inductive definition of a functional relation from this general theorem about the validity of inductive definitions of relations by proving that, under certain conditions (namely, those mentioned in Theorem 253), the relation so defined will be functional. ${ }^{24}$

An example should help to explain the theorem. Let $\mathrm{Q} \xi \eta$ relate $\mathrm{m}$ to $\mathrm{n}$ just in case $\mathrm{n}$ is a prime multiple of $\mathrm{m}$; that is, define:

$$
\text { Qmn } \equiv \mathrm{df} \exists \mathrm{p}[\operatorname{Prime}(\mathrm{p}) \& \mathrm{n}=\mathrm{pm}]
$$

Now, it is a theorem of arithmetic that, for every natural number $m \geq 1$, there is some $\mathrm{n}$ such that Qmn:

$$
\mathscr{F}=(\text { Pred })(1, \mathrm{~m}) \rightarrow \exists \mathrm{y} . \text { Qmy }
$$

Hence, the Q-series beginning with 1 is endless. By Theorem 241, $\zeta$, then:

$$
\forall \mathrm{x}\left\{\mathscr{F}^{=}(\operatorname{Pred})(0, \mathrm{x}) \rightarrow \exists \mathrm{y}\left[\mathscr{F}^{\wedge}(\operatorname{Pred} \pi \mathrm{Q} ; 0,1)(\mathrm{x}, \mathrm{y}) \& \mathscr{F}^{=}(\mathrm{Q})(1, \mathrm{y})\right]\right\}
$$

That is, $\mathscr{F}^{\wedge}\{\operatorname{Pred}(\xi, \eta) \pi \exists \mathrm{p}[\operatorname{Prime}(\mathrm{p}) \& \tau=\mathrm{p} \zeta] ; 0,1\}(\alpha, \beta)$ is a relation whose domain consists of all natural numbers and whose range is wholly contained in the Q-series beginning with 1 . Moreover,

$$
\mathscr{F}^{\wedge}[(\operatorname{Pred}(\xi, \eta) \pi \exists \mathrm{p}(\operatorname{Prime}(\mathrm{p}) \& \tau=\mathrm{p} \zeta)) ; 0,1](\mathrm{m}, \mathrm{x})
$$

holds just in case $\mathrm{x}$ is a product of $\mathrm{m}$ (not necessarily distinct) primes, as can easily be seen. ${ }^{25}$

The proof of Theorem 241, $\zeta$ itself is of no great interest and will be omitted.

\section{Functionality and the n-Ancestral}

We turn then to the proof of Frege's Theorem 253, for which we need two lemmas. Recall that Theorem 253 is:

$\operatorname{Func}(\mathrm{R}) \& \operatorname{Func}(\mathrm{Q}) \& \neg \exists \mathrm{y}\left[\mathscr{F}^{=}(\mathrm{R})(\mathrm{m}, \mathrm{y}) \& \mathscr{F}(\mathrm{R})(\mathrm{y}, \mathrm{y})\right] \rightarrow \operatorname{Func}\left(\mathscr{F}^{\wedge}[\mathrm{R} \pi \mathrm{Q} ; \mathrm{m}, \mathrm{a}]\right)$

The first of the lemmas, Theorem 252, is essentially:

$\operatorname{Func}(\mathrm{R}) \& \operatorname{Func}(\mathrm{Q}) \rightarrow \operatorname{Func}(\mathrm{R} \pi \mathrm{Q})$

That is: If $\mathrm{R} \xi \eta$ and $\mathrm{Q} \xi \eta$ are functional, then $(\mathrm{R} \pi \mathrm{Q})(\xi, \eta ; \zeta, \tau)$ is functional. However, since the notion of functionality has so far been defined only for two-place relations, the consequent is not yet well-formed. Now, for Frege, the coupling of two relations is a relation between ordered pairs, whence it is indeed a two-place relation: To say that $(\mathrm{R} \pi \mathrm{Q})[\xi, \eta]$ is functional is then to say that:

$$
\forall \mathrm{x} \forall \mathrm{y} \forall \mathrm{z}[(\mathrm{R} \pi \mathrm{Q})(\mathrm{x}, \mathrm{y}) \&(\mathrm{R} \pi \mathrm{Q})(\mathrm{x}, \mathrm{z}) \rightarrow \mathrm{y}=\mathrm{z}]
$$

Since ' $x$ ' and ' $y$ ' here range over ordered pairs, we may, as earlier, reduce this proposition to: 


$$
\forall \mathrm{x} \forall \mathrm{y} \forall \mathrm{z} \forall \mathrm{w} \forall \mathrm{u} \forall \mathrm{v}[(\mathrm{R} \pi \mathrm{Q})[(\mathrm{x} ; \mathrm{y}),(\mathrm{z} ; \mathrm{w})] \&(\mathrm{R} \pi \mathrm{Q})[(\mathrm{x} ; \mathrm{y}),(\mathrm{u} ; \mathrm{v})] \rightarrow \mathrm{z}=\mathrm{u} \& \mathrm{w}=\mathrm{v}]
$$

We therefore define:

$$
\text { Func }_{2,2}(\mathrm{R} \xi, \eta ; \zeta, \tau) \equiv \mathrm{df} \forall \mathrm{x} \forall \mathrm{y} \forall \mathrm{z} \forall \mathrm{w} \forall \mathrm{u} \forall \mathrm{v}[\mathrm{Rx}, \mathrm{y} ; \mathrm{z}, \mathrm{w} \& \mathrm{Rx}, \mathrm{y} ; \mathrm{u}, \mathrm{v} \rightarrow \mathrm{z}=\mathrm{u} \& \mathrm{w}=\mathrm{v}]
$$

That is: A four-place relation $R \xi, \eta ; \zeta, \tau$ is 2,2 -functional if, and only if, whenever the pair of $x$ and $y$ stands in it to the pair of $\mathrm{z}$ and $\mathrm{w}$ and to the pair of $\mathrm{u}$ and $\mathrm{v}$, the pair of $\mathrm{z}$ and $\mathrm{w}$ is the pair of $\mathrm{u}$ and $\mathrm{v}$. We may then write Theorem 252 as:

$$
\operatorname{Func}(\mathrm{R}) \& \operatorname{Func}(\mathrm{Q}) \rightarrow \mathrm{Func}_{2,2}(\mathrm{R} \pi \mathrm{Q})
$$

The second needed lemma is Theorem 248:

$$
\operatorname{Func}_{2,2}(\mathrm{R} \pi \mathrm{Q}) \& \neg \exists \mathrm{x}\left[\mathscr{T}^{=}(\mathrm{R})(\mathrm{m}, \mathrm{x}) \& \mathscr{F}^{=}(\mathrm{R})(\mathrm{x}, \mathrm{x})\right] \rightarrow \operatorname{Func}\left(\mathscr{F}^{\wedge}[\mathrm{R} \pi \mathrm{Q} ; \mathrm{m}, \mathrm{a}]\right)
$$

That is: If $(\mathrm{R} \pi \mathrm{Q})(\xi, \eta ; \zeta, \tau)$ is 2,2 -functional and no member of the R-series beginning with $\mathrm{m}$ follows after itself in the R-series, then $\mathscr{F}^{\wedge}[(\mathrm{R} \pi \mathrm{Q}) ; \mathrm{m}, \mathrm{a}](\xi, \eta)$ is functional. Theorem 253 is an immediate consequence of these two lemmas.

The proof of Theorem 252 is straightforward. ${ }^{26}$

The proof of Theorem 248, in outline, is as follows. By definition, if $\mathscr{F} \wedge[R \pi Q ; m, a](\xi, \eta)$ is not functional, then, for some b, c, and d, we must have $\mathscr{F}^{\wedge}[\mathrm{R} \pi \mathrm{Q} ; \mathrm{m}, \mathrm{a}](\mathrm{b}, \mathrm{c})$ and $\mathscr{F}^{\wedge}[\mathrm{R} \pi \mathrm{Q} ; \mathrm{m}, \mathrm{a}](\mathrm{b}, \mathrm{d})$, where $\mathrm{c} \neq \mathrm{d}$. By the definition of ' $\mathscr{F}^{\wedge}$ ', then, $\mathscr{T}^{=}(\mathrm{R} \pi \mathrm{Q})(\mathrm{m}, \mathrm{a} ; \mathrm{b}, \mathrm{c})$ and $\mathscr{T}^{=}(\mathrm{R} \pi \mathrm{Q})(\mathrm{m}, \mathrm{a} ; \mathrm{b}, \mathrm{d})$. Now, intuitively, during the inductive 'process' of assigning members of the R-series beginning with $m$ their 'values', $b$ must have been assigned a value twice. For, at each step in the process, exactly one member of the Rseries beginning with $\mathrm{m}$ is assigned exactly one value (since $(\mathrm{R} \pi \mathrm{Q})(\xi, \eta ; \zeta, \tau)$ is 2,2 -functional); moreover, the process of assigning values proceeds from one member of the R-series beginning with $\mathrm{m}$ to a unique next member of the R-series beginning with $\mathrm{m}$ (since $\mathrm{R} \xi \eta$ is functional). So, if $\mathrm{b}$ is to get two values, it must occur twice in this series. But that will imply that $\mathrm{b}$ follows after itself in the series, contradicting the supposition no member of the R-series beginning with $\mathrm{m}$ follows after itself.

The central lemma in Frege's proof of Theorem 248 is the famous Theorem 133 from Frege's Begriffsschrift, here appearing as Theorem $243:^{27}$

$$
\operatorname{Func}(\mathrm{R}) \& \mathscr{F}=(\mathrm{R})(\mathrm{m}, \mathrm{t}) \& \mathscr{F}^{=}(\mathrm{R})(\mathrm{m}, \mathrm{n}) \rightarrow[\mathscr{F}(\mathrm{R})(\mathrm{n}, \mathrm{t}) \vee \mathscr{F}=(\mathrm{R})(\mathrm{t}, \mathrm{n})]
$$

That is: If $R \xi \eta$ is functional and both $t$ and $n$ belong to the R-series beginning with $m$, then either $n$ belongs to the R-series beginning with $\mathrm{t}$ or $\mathrm{t}$ follows after $\mathrm{n}$ in the R-series. It is this theorem which will 
imply that any object which "occurs twice" in the R-series beginning with $\mathrm{m}$ follows after itself in the Rseries.

What we need is in fact not Theorem 243, but its analogue for the 2-ancestral, Theorem $243_{2}$ :

$\operatorname{Func}_{2,2}(\mathrm{R}) \& \mathscr{F}^{=}(\mathrm{R})(\mathrm{m}, \mathrm{a} ; \mathrm{n}, \mathrm{y}) \& \mathscr{F}^{=}(\mathrm{R})(\mathrm{m}, \mathrm{a} ; \mathrm{s}, \mathrm{t}) \rightarrow\left[\mathscr{F}(\mathrm{R})(\mathrm{n}, \mathrm{y} ; \mathrm{s}, \mathrm{t}) \vee \mathscr{F}^{=}(\mathrm{R})(\mathrm{s}, \mathrm{t} ; \mathrm{n}, \mathrm{y})\right]$

We need two other lemmas:

$$
\begin{aligned}
& \text { 244: } \mathscr{F}(\mathrm{R} \pi \mathrm{Q})(\mathrm{x}, \mathrm{y} ; \mathrm{z}, \mathrm{w}) \rightarrow \mathscr{F}(\mathrm{R})(\mathrm{x}, \mathrm{z}) \\
& 246 \mathscr{F}^{=}(\mathrm{R} \pi \mathrm{Q})(\mathrm{m}, \mathrm{a} ; \mathrm{x}, \mathrm{y}) \rightarrow \mathscr{F}^{=}(\mathrm{R})(\mathrm{m}, \mathrm{x})
\end{aligned}
$$

The derivation of Theorem 248 from these lemmas provides a nice illustration of the power of the 2ancestral. Suppose that $(\mathrm{R} \pi \mathrm{Q})(\xi, \eta ; \zeta, \tau)$ is 2,2-functional, that no member of the R-series beginning with m follows itself, and (as above) that $\mathscr{F}^{=}(\mathrm{R} \pi \mathrm{Q})(\mathrm{m}, \mathrm{a} ; \mathrm{x}, \mathrm{y})$ and $\mathscr{F}^{=}(\mathrm{R} \pi \mathrm{Q})(\mathrm{m}, \mathrm{a} ; \mathrm{x}, \mathrm{z})$. Note that, by Theorem 246, $\mathscr{F}=(\mathrm{R})(\mathrm{m}, \mathrm{x})$. By Theorem $243_{2}$, one of the following three cases must hold:

$$
\begin{aligned}
& \text { (i) } \mathscr{F}(\mathrm{R} \pi \mathrm{Q})(\mathrm{x}, \mathrm{y} ; \mathrm{x}, \mathrm{z}) \\
& \text { (ii) } \mathscr{F}(\mathrm{R} \pi \mathrm{Q})(\mathrm{x}, \mathrm{z} ; \mathrm{x}, \mathrm{y}) \\
& \text { (iii) } \mathrm{x}=\mathrm{x} \& \mathrm{y}=\mathrm{z}
\end{aligned}
$$

But, if either (i) or (ii), then $\mathscr{F}(\mathrm{R})(\mathrm{x}, \mathrm{x})$, by Theorem 244 , contradicting the assumption that the R-series beginning with $\mathrm{m}$ is simple. Hence, (iii) must hold, $\mathrm{y}=\mathrm{z}$, and $\mathscr{F}^{\wedge}(\mathrm{R} \pi \mathrm{Q} ; \mathrm{m}, \mathrm{a})(\xi, \eta)$ is functional.

The proofs of the lemmas are not difficult and, except for that of Theorem $243_{2}$ (which is in Appendix II), will be omitted.

\section{Theorem 263 in the Context of Frege's Development of Arithmetic}

We have thus completed our discussion of Frege's proof of Theorem 263. As we have seen, the proof can be reconstructed in Fregean Arithmetic, with or without the use of the ordered pair axiom. Moreover, Frege's proofs of the crucial Theorems 254 and 259, of which the Isomorphism Theorem is an immediate consequence, can be reconstructed in second-order logic, either with or without the use of the ordered pair axiom. Since Frege was perfectly aware that his uses of Axiom V in such proofs are dispensible, ${ }^{28}$ Frege did, in effect, prove Theorem 263 in Fregean Arithmetic, augemented by the ordered pair axiom, and the Isomorphism Theorem in second-order logic, augmented by the ordered pair axiom. I 
have suggested, further, that Frege knew his use of ordered pairs to be dispensible and so knew, and effectively showed, these also to be theorems of second-order arithmetic and logic simpliciter.

The significance of Theorem 263, in the context of Frege's project, is far from clear, however; Frege does not say very much about it. In the Introduction, for example, he writes:

It might be thought that the propositions concerning the number 'Endlos' could have been omitted; to be sure, they are not necessary for the foundation of arithmetic in its traditional compass, but their derivation is for the most part simpler than that of the corresponding propositions for finite numbers and can serve as preparation for it ( $G g \mathrm{p}$. v).

But, surely, the Theorem is of greater significance than that: Grundgesetze is not just a random collection of results, and it is implausible in the extreme that Frege should have included the proof of Theorem 263 in what was intended to be his magnum opus just because it is similar to, and simpler than, the proof of a corresponding result for finite numbers. ${ }^{29}$

Theorem 263, together with Frege's Theorem 207, does yield a characterization of concepts whose number is Endlos. Theorem 207 is just the converse of Theorem 263:

$$
\begin{aligned}
& \text { Nx:Gx }=\infty \rightarrow \\
& \quad \exists \mathrm{Q}\{\operatorname{Func}(\mathrm{Q}) \& \neg \exists \mathrm{x} . \mathscr{F}(\mathrm{Q})(\mathrm{x}, \mathrm{x}) \& \forall \mathrm{x}[\mathrm{Gx} \rightarrow \exists \mathrm{y} \cdot \mathrm{Qxy}] \& \exists \mathrm{x} \forall \mathrm{y}[\mathrm{Fy} \equiv \\
& \mathscr{F}=(\mathrm{Q})(\mathrm{x}, \mathrm{y})]\}
\end{aligned}
$$

Thus, the number of Gs is Endlos just in case the Gs can be ordered as a simply endless series beginning, say, with an object a. It follows from Frege's Theorem 243 that the Q-series beginning with a is linearly ordered by $\mathscr{F}(\mathrm{Q})(\xi, \eta)$; moreover, Theorem 359 , which is a generalization of the least number principle, implies that the Q-series beginning with a is well-ordered by $\mathscr{F}(\mathrm{Q})(\xi, \eta)$. And so, Theorems 207, 263, 243, and 359 together imply that the number of Gs is Endlos if and only if the Gs can be ordered as an $\omega$-sequence. Presumably, part of Frege's reason for proving Theorem 263 is that he intends so to characterize countably infinite concepts. ${ }^{30}$

Further, Theorem 263 plays an important role in the proof of Theorem 428:

$$
\mathrm{Nx}: \mathrm{Gx}=\infty \& \forall \mathrm{x}(\mathrm{Fx} \rightarrow \mathrm{Gx}) \rightarrow[\mathrm{Nx}: \mathrm{Fx}=\infty \vee \mathscr{F}=(\operatorname{Pred})(0, \mathrm{Nx}: \mathrm{Fx})]
$$


That is: If the number of Gs is Endlos and every F is a G, then, either the number of Fs is Endlos or the number of Fs is finite; i.e., every concept subordinate to a concept whose number is countably infinite is countable. This result is of some importance, but its significance is not immediately apparent either. ${ }^{31}$

The real point of Theorem 263, it seems to me, is not revealed by examination of its use in Grundgesetze. A modern reader would naturally take the theorem--or, more generally, the Isomorphism Theorem--to show that any two structures satisfying certain conditions are isomorphic. Recall that the Isomorphism Theorem is:

$$
\begin{gathered}
\text { Func(Q) \& } \neg \exists \mathrm{x}(\mathscr{F}=(\mathrm{Q})(\mathrm{a}, \mathrm{x}) \& \mathscr{F}(\mathrm{Q})(\mathrm{x}, \mathrm{x})) \& \forall \mathrm{x}\left(\mathscr{F}^{=}(\mathrm{Q})(\mathrm{a}, \mathrm{x}) \rightarrow \exists \mathrm{y} . \mathrm{Qxy}\right) \& \\
\text { Func(R) \& } \neg \exists \mathrm{x}\left(\mathscr{F}^{=}(\mathrm{R})(\mathrm{m}, \mathrm{x}) \& \mathscr{F}(\mathrm{R})(\mathrm{x}, \mathrm{x})\right) \& \forall \mathrm{x}\left(\mathscr{F}^{=}(\mathrm{R})(\mathrm{m}, \mathrm{x}) \rightarrow \exists \mathrm{y} . \mathrm{Rxy}\right) \rightarrow \\
\operatorname{Map}\left(\mathscr{F}^{\wedge}((\mathrm{R} \pi \mathrm{Q}) ; \mathrm{m}, \mathrm{a})\right)\left(\mathscr{F}^{=}(\mathrm{R})(\mathrm{m}, \xi), \mathscr{F}^{=}(\mathrm{Q})(\mathrm{a}, \xi)\right) \& \\
\operatorname{Map}\left[\operatorname{Conv}\left(\mathscr{F}^{\wedge}((\mathrm{R} \pi \mathrm{Q}) ; \mathrm{m}, \mathrm{a})\right)\right]\left(\mathscr{F}^{=}(\mathrm{Q})(\mathrm{a}, \xi), \mathscr{F}^{=}(\mathrm{R})(\mathrm{m}, \xi)\right)
\end{gathered}
$$

The conditions in question are thus:

1. Func(P)

$$
\begin{aligned}
& \text { 2. } \neg \exists \mathrm{x}[\mathscr{F}=(\mathrm{P})(\mathrm{a}, \mathrm{x}) \& \mathscr{T}(\mathrm{P})(\mathrm{x}, \mathrm{x})] \\
& \text { 3. } \forall \mathrm{x}[\mathscr{F}=(\mathrm{P})(\mathrm{a}, \mathrm{x}) \rightarrow \exists \mathrm{y} . \mathrm{Pxy}]
\end{aligned}
$$

Earlier, we called a series whose determining relation satisfies these conditions a simply endless series and said that the Isomporphism Theorem shows that all simply endless series are isomorphic. Better to understand the significance of this Theorem, let us write the conditions slightly differently. We write ' 0 ' for 'a' and introduce a concept $\mathrm{N} \xi$, as in Theorem 263:

$$
\begin{aligned}
& \text { 1. } \operatorname{Func}(\mathrm{P}) \\
& \text { 2. } \neg \exists \mathrm{x}[\mathrm{Nx} \& \mathscr{F}(\mathrm{P})(\mathrm{x}, \mathrm{x})] \\
& \text { 3. } \forall \mathrm{x}[\mathrm{Nx} \rightarrow \exists \mathrm{y} \cdot \mathrm{Pxy}] \\
& \text { 4. } \mathrm{Nx} \equiv \mathscr{F}=(\mathrm{P})(0, \mathrm{x})
\end{aligned}
$$

Conditions (1)-(4) are axioms for arithmetic: The more familiar Dedekind-Peano Axioms are easily derived from them (and conversely). ${ }^{32}$ What the proof of Theorem 263 shows is thus that any two structures satisfying Frege's axioms for arithmetic are isomorphic.

As was said, that Frege so intended the proof can not be shown by quoting him: He is not very good about explaining the significance of the theorems he proves. There is nevertheless reason to think 
that he did so intend it: Namely, the hypothesis that the proof is to show that any structures satisfying these axioms for arithmetic are isomorphic resolves an annoying puzzle about the structure of Part II of Grundgesetze. What is puzzling is the status accorded to the proof that no natural number follows itself in the Pred-series: This theorem is granted its very own section, advertised as a major result. The modern reader, with the Dedekind-Peano Axioms firmly in mind, naturally reads it as but an important lemma in the proof that every natural number has a successor. But Frege accords it pride of place: For it is among his axioms for arithmetic.

It is worth noting, too, that Frege's axioms are extremely intuitive. The natural numbers are the members of a series which begins with the number zero (Axiom 4, induction); each number in this series is followed by one (Axiom 3, that every natural number has a successor) and exactly one number (Axiom 1 , that $\operatorname{Pred}(\xi, \eta)$ is functional). And, so to speak, each number in the series is followed by a new number, by one which has not previously occurred in the series: That is, the successor of a natural number never precedes it in the number-series. Formally:

$\neg \exists \mathrm{x}[\mathrm{Nx} \& \mathrm{P}(\mathrm{x}, \mathrm{y}) \& \mathscr{F}(\mathrm{P})(\mathrm{y}, \mathrm{x})]$

As is easily seen, however, in the presence of the other axioms, this is equivalent to Frege's Axiom 2, that no natural number follows after itself in the number-series. It is, of course, essential that Frege's axioms should be intuitive and connected with our ordinary applications of arithmetic: For Frege intends to show that arithmetic is a branch of logic, not that some formal theory which looks something like arithmetic can be developed within something which looks like logic.

The import of the second axiom is, indeed, explained in detail by Frege, in a passage which is worth quoting in full:

The proposition...says that no object which belongs to the number-series beginning with zero follows after itself in the number-series. Instead of this, we can also say: "No finite number follows after itself in the number-series". The importance of this proposition will be made more evident by the following considerations. If we determine the number belonging to a concept $\Phi(\xi)$, or, as one normally says, if we count the objects falling under the concept $\Phi(\xi)$, then we successively associate these objects with the numberwords from "one" up to a number-word " $N$ ", which will be determined by the associating 
relation's mapping the concept $\Phi(\xi)$ into the concept "member of the series of numberwords from 'one' to ' $N$ " and the converse relation's mapping the latter concept into the former. " $N$ " then denotes the sought number; i.e., $N$ is this number. This process of counting may be carried out in various ways, since the associating relation is not completely determined.

The question arises whether, by another choice of this relation, one could reach another number-word ' $M$ '. Then, by our assumptions, $M$ would be the same number as $N$, but, at the same time, one of these two number-words would follow after the other, e.g., ' $N$ ' would follow ' $M$ '. Then $N$ would follow in the number-series after $M$, which means that it would follow after itself. That is excluded by our proposition concerning finite numbers $(G g$ I $§ 108)$.

That is to say: That the result of the process of counting--the number-word one reaches by counting--is well-determined is, according to Frege, a consequence of the fact that no natural number follows after itself. And so, this fact about the natural numbers has a special, and central, role to play in helping us to understand, or in providing a justification for, our ordinary employment of arithmetic.

One might wonder, however, whether Isomorphism Theorem can possibly have the significance I have suggested it has. After all, one might say, Frege does not even write it down.--It should, however, be remembered that Grundgesetze is a mathematical work and that Frege surely would have assumed that his readers could make certain inferences for themselves: The Isomorphism Theorem is, as we have seen, an utterly trivial consequence of Theorems 254 and 259 which no careful reader can miss. Indeed, in Frege's proof of Theorem 263, Theorem 259 is not needed in the general form in which Frege proves it; all he needs is that $\mathscr{F}^{\wedge}(\mathrm{Q} \pi$ Pred; a, 0$)(\xi, \eta)$ is the converse of $\mathscr{F}^{\wedge}($ Pred $\pi \mathrm{Q} ; 0, \mathrm{a})(\xi, \eta)$. The fact that he does prove Theorem 259 in its more general form indicates that he intends the reader to realize that a proof like that of Theorem 263 could be given of a more general result, namely, the Isomorphism Theorem.

Besides, one should not put too much weight on the distinction between what Frege writes down and what he leaves for the reader to infer. Frege never explicitly records mathematical induction as a theorem either, and he can hardly be said to have been oblivious to its import. 


\section{Closing}

If the foregoing account of Frege's proof of Theorem 263 and its significance is correct, then the evaluation of his work in Grundgesetze must change. For the most part, Grundgesetze has been ignored: When it has not been ignored, it has usually been dismissed, as if that were more charitable than the alternative, which would be ridicule. As we have seen, however, not only does Grundgesetze contain a derivation of axioms for arithmetic, in second-order logic, from Hume's Principle, it contains a proof, in Fregean Arithmetic, that Frege's own axioms for arithmetic determine a class of structures isomorphic to the natural numbers. Moreover, it contains a proof, in pure second-order logic, of the more general fact that all structures satisfying these axioms are isomorphic.

Now, I do not want here to compare the relative merits of Frege's and Dedekind's proofs of these theorems, and I am surely not going to suggest that Frege's work in these areas had very much impact on the working mathematicians of his day. However, the recent tendency, among some philosophers, to dismiss Frege's work as largely irrelevant simply can not be sustained, unless one is prepared, as I for one am not, to dismiss Was Sind? in the same breath. ${ }^{33}$ 


\section{Appendix I}

\section{Proof that $\mathscr{F}^{\wedge}(\mathrm{R} \pi \mathrm{Q} ; \mathrm{m}, \mathrm{a})(\xi, \eta)$ is Order-Preserving}

We prove that, if the R-series beginning with $\mathrm{m}$ and the Q-series beginning with a are simply endless, then $\mathscr{F}^{\wedge}(\mathrm{R} \pi \mathrm{Q} ; \mathrm{m}, \mathrm{a})(\xi, \eta)$ is order-preserving. The ordering relations which $\mathscr{F}^{\wedge}(\mathrm{R} \pi \mathrm{Q} ; \mathrm{m}, \mathrm{a})(\xi, \eta)$ respects are the weak ancestrals of $\mathrm{R} \xi \eta$ and $\mathrm{Q} \xi \eta$. To show that $\mathscr{F} \wedge(\mathrm{R} \pi \mathrm{Q} ; \mathrm{m}, \mathrm{a})(\xi, \eta)$ and its converse are order-preserving, it is sufficient, in light of Theorem 259, to show that:

$$
\mathscr{F}^{\wedge}(\mathrm{R} \pi \mathrm{Q} ; \mathrm{m}, \mathrm{a})(\mathrm{b}, \mathrm{x}) \& \mathscr{F}^{\wedge}(\mathrm{R} \pi \mathrm{Q} ; \mathrm{m}, \mathrm{a})(\mathrm{c}, \mathrm{y}) \rightarrow[\mathscr{F}(\mathrm{R})(\mathrm{b}, \mathrm{c}) \equiv \mathscr{F}(\mathrm{Q})(\mathrm{x}, \mathrm{y})]
$$

Suppose, then, that $\mathscr{F}^{\wedge}(\mathrm{R} \pi \mathrm{Q} ; \mathrm{m}, \mathrm{a})(\mathrm{b}, \mathrm{x})$ and $\mathscr{F}^{\wedge}(\mathrm{R} \pi \mathrm{Q} ; \mathrm{m}, \mathrm{a})(\mathrm{c}, \mathrm{y})$. By definition, $\mathscr{F}=(\mathrm{R} \pi \mathrm{Q})(\mathrm{m}, \mathrm{a} ; \mathrm{b}, \mathrm{x})$ and $\mathscr{F}=(\mathrm{R} \pi \mathrm{Q})(\mathrm{m}, \mathrm{a} ; \mathrm{c}, \mathrm{y})$. Hence, by Theorem 243: (i) $\mathscr{F}(\mathrm{R} \pi \mathrm{Q})(\mathrm{b}, \mathrm{x} ; \mathrm{c}, \mathrm{y})$; (ii) $\mathscr{F}(\mathrm{R} \pi \mathrm{Q})(\mathrm{c}, \mathrm{y} ; \mathrm{b}, \mathrm{x})$; or, (iii) b=c $\& \mathrm{x}=\mathrm{y}$. Note that $\mathscr{F}=(\mathrm{R})(\mathrm{m}, \mathrm{b})$, by Theorem 232. Now, suppose $\mathscr{F}(\mathrm{R})(\mathrm{b}, \mathrm{c})$; if (iii), then $\mathscr{F}(\mathrm{R})(\mathrm{b}, \mathrm{b})$, contradicting the fact that the R-series beginning with $\mathrm{m}$ is simple. If (ii), then, by Theorem 232, $\mathscr{F}(\mathrm{R})(\mathrm{c}, \mathrm{b})$, hence $\mathscr{F}(\mathrm{R})(\mathrm{b}, \mathrm{b})$, by the transitivity of the ancestral, again contradicting the simplicity of the R-series beginning with m. Hence, (i) must hold: So, by Theorem 232, again, $\mathscr{F}(\mathrm{Q})(\mathrm{x}, \mathrm{y})$.

By a parallel argument, if $\mathscr{F}(\mathrm{Q})(\mathrm{x}, \mathrm{y})$, then (i) must hold; so $\mathscr{F}(\mathrm{R})(\mathrm{b}, \mathrm{c})$, by Theorem 232. 


\section{Appendix II}

Theorems Concerning the n-Ancestral, and Proofs of Them

$123_{\mathrm{n}}: \mathscr{F}_{\mathrm{n}}(\mathrm{R})(\mathbf{a}, \mathbf{b}) \& \forall \mathbf{x}(\mathrm{Rax} \rightarrow \mathrm{Fx}) \& \forall \mathbf{x} \forall \mathbf{y}(\mathrm{Fx} \& \mathrm{Rxy} \rightarrow \mathrm{Fy}) \rightarrow \mathrm{Fb}$

$127_{\mathrm{n}}: \forall \mathrm{F}[\forall \mathbf{x}(\mathrm{Rax} \rightarrow \mathrm{F} \mathbf{x}) \& \forall \mathbf{x} \forall \mathbf{y}(\mathrm{Fx} \& \mathrm{Rxy} \rightarrow \mathrm{Fy}) \rightarrow \mathrm{Fb}] \rightarrow \mathscr{F}_{\mathrm{n}}(\mathrm{R})(\mathbf{a}, \mathbf{b})$

Both by definition.

$124_{\mathrm{n}}: \mathscr{T}_{\mathrm{n}}(\mathrm{R})(\mathbf{a}, \mathbf{b}) \rightarrow \exists \mathbf{x} \cdot \mathrm{Rxb}$

$\left(123_{\mathrm{n}}\right)$, with $\exists \mathbf{x} . R \mathbf{x} \xi$. If Ray, then, plainly, $\exists \mathbf{x}$.Rxy. Suppose $\exists \mathbf{x}$.Rxy and Ryz. Obviously, $\exists \mathbf{x} . R \mathbf{x z}$.

$128_{\mathrm{n}}: \mathscr{F}_{\mathrm{n}}(\mathrm{R})(\mathbf{a}, \mathbf{b}) \& \mathrm{Fa} \& \forall \mathbf{x} \forall \mathbf{y}(\mathrm{Fx} \& \mathrm{R} \mathbf{x y} \rightarrow \mathrm{Fy}) \rightarrow \mathrm{Fb}$

If $\forall \mathbf{x} \forall \mathbf{y}(\mathrm{Fx} \& \mathrm{Rxy} \rightarrow \mathrm{Fy})$, then $\forall \mathbf{y}(\mathrm{Fa} \&$ Ray $\rightarrow$ Fy $)$; hence, if Fa, then $\forall \mathrm{y}($ Ray $\rightarrow$ Fy $)$. Apply $\left(123_{\mathrm{n}}\right)$.

$129_{\mathrm{n}}: \mathscr{F}_{\mathrm{n}}(\mathrm{R})(\mathbf{a}, \mathbf{b}) \& \mathrm{R} \mathbf{c a} \rightarrow \mathscr{F}_{\mathrm{n}}(\mathrm{R})(\mathbf{c}, \mathbf{b})$

To apply $\left(127_{\mathrm{n}}\right)$, suppose $\mathrm{F} \boldsymbol{\xi}$ is hereditary and that $\forall \mathbf{x}(\mathrm{R} \mathbf{c x} \rightarrow \mathrm{Fx})$. Since Rca, Fa. By $\left(128_{\mathrm{n}}\right)$, Fb.

$131_{\mathrm{n}}: \operatorname{Rab} \rightarrow \mathscr{T}_{\mathrm{n}}(\mathrm{R})(\mathbf{a}, \mathbf{b})$

Suppose F $\boldsymbol{\xi}$ is hereditary and that $\forall \mathbf{x}(\operatorname{Rax} \rightarrow F \mathbf{x})$. Since Rab, Fb. Apply $\left(127_{\mathrm{n}}\right)$.

$132_{\mathrm{n}}: \mathscr{F}_{\mathrm{n}}{ }^{=}(\mathrm{R})(\mathbf{a}, \mathbf{b}) \& \mathrm{R} \mathbf{c a} \rightarrow \mathscr{F}_{\mathrm{n}}(\mathrm{R})(\mathbf{c}, \mathbf{b})$

Suppose $\mathbf{a}=\mathbf{b}$ and Rca. Then Rcb, so $\mathscr{F}_{\mathrm{n}}(\mathrm{R})(\mathbf{c}, \mathbf{b})$, by $\left(131_{\mathrm{n}}\right)$. Hence, with $\left(129_{\mathrm{n}}\right)$ :

$\left[\mathbf{a}=\mathbf{b} \vee \mathscr{F}_{\mathrm{n}}(\mathrm{R})(\mathbf{a}, \mathbf{b})\right] \& \mathrm{R} \mathbf{c a} \rightarrow \mathscr{F}_{\mathrm{n}}(\mathrm{R})(\mathbf{c}, \mathbf{b})$

$133_{\mathrm{n}}: \mathscr{F}_{\mathrm{n}}(\mathrm{R})(\mathbf{a}, \mathbf{b}) \& \mathrm{Rbc} \rightarrow \mathscr{F}_{\mathrm{n}}(\mathrm{R})(\mathbf{a}, \mathbf{c})$

By $\left(127_{\mathrm{n}}\right)$. Suppose $\mathrm{F} \xi$ hereditary, $\forall \mathbf{x}(\operatorname{Rax} \rightarrow \mathrm{Fx})$. Since $\mathscr{F}_{\mathrm{n}}(\mathrm{R})(\mathbf{a}, \mathbf{b}), \mathrm{Fb}$. Since Rbc and $\mathrm{F} \xi$ is hereditary,

Fc.

$134_{\mathrm{n}}: \mathscr{F}_{\mathrm{n}}=(\mathrm{R})(\mathbf{a}, \mathbf{b}) \& \mathrm{Rbc} \rightarrow \mathscr{F}_{\mathrm{n}}(\mathrm{R})(\mathbf{a}, \mathbf{c})$

From $\left(133_{n}\right)$, as $\left(132_{n}\right)$ from $\left(129_{n}\right)$.

$136_{\mathrm{n}}: \mathscr{F}_{\mathrm{n}}(\mathrm{R})(\mathbf{a}, \mathbf{b}) \rightarrow \mathscr{F}_{\mathrm{n}}=(\mathrm{R})(\mathbf{a}, \mathbf{b})$

$139_{\mathrm{n}}: \mathbf{a}=\mathbf{b} \rightarrow \mathscr{F}_{\mathrm{n}}=(\mathrm{R})(\mathbf{a}, \mathbf{b})$

$140_{\mathrm{n}}: \mathscr{F}_{\mathrm{n}}=(\mathrm{R})(\mathbf{a}, \mathbf{a})$

All immediate from the definition of " $\mathscr{F}_{\mathrm{n}}="$ (and identity).

$137 \mathrm{n}: \mathscr{T}^{=}{ }_{\mathrm{n}}(\mathrm{R})(\mathbf{a}, \mathbf{b}) \& \mathrm{Rbc} \rightarrow \mathscr{F}_{\mathrm{n}}=(\mathrm{R})(\mathbf{a}, \mathbf{c})$

From $\left(134_{n}\right)$ and $\left(136_{n}\right)$. 
$141_{\mathrm{n}}: \mathscr{F}_{\mathrm{n}}(\mathrm{R})(\mathbf{a}, \mathbf{b}) \rightarrow \exists \mathbf{x}\left[\mathscr{F}_{\mathrm{n}}=(\mathrm{R})(\mathbf{a}, \mathbf{x}) \& \mathrm{R} \mathbf{x b}\right]$

$\left(123_{\mathrm{n}}\right)$, with $\exists \mathbf{x}\left[\mathscr{F}_{\mathrm{n}}=(\mathrm{R})(\mathbf{a}, \mathbf{x}) \& \mathrm{R} \mathbf{x} \xi\right]$. Suppose Ray. Then, by $\left(140_{\mathrm{n}}\right)$, Ray and $\mathscr{F}_{\mathrm{n}}=(\mathrm{R})(\mathbf{a}, \mathbf{a})$; hence,

$\exists \mathbf{x}\left[\mathscr{F}_{\mathrm{n}}{ }^{=}(\mathrm{R})(\mathbf{a}, \mathbf{x}) \& \mathrm{R} \mathbf{x y}\right]$. Suppose $\exists \mathbf{x}\left[\mathscr{F}_{\mathrm{n}}{ }^{=}(\mathrm{R})(\mathbf{a}, \mathbf{x}) \& \mathrm{R} \mathbf{x y}\right]$ and Ryz. Since $\mathscr{F}_{\mathrm{n}}{ }^{=}(\mathrm{R})(\mathbf{a}, \mathbf{x}) \& \mathrm{R} \mathbf{x y}$,

$\mathscr{F}_{\mathrm{n}}{ }^{=}(\mathrm{R})(\mathbf{a}, \mathbf{y})$, by $\left(137_{\mathrm{n}}\right)$. So $\mathscr{F}_{\mathrm{n}}{ }^{\mathrm{N}}(\mathrm{R})(\mathbf{a}, \mathbf{y}) \& \mathrm{Ryz}$, so $\exists \mathbf{x}\left[\mathscr{F}_{\mathrm{n}}{ }^{\mathrm{N}}(\mathrm{R})(\mathbf{a}, \mathbf{x}) \& \mathrm{Rxz}\right]$. Done.

$144_{\mathrm{n}}: \mathscr{F}_{\mathrm{n}}=(\mathrm{R})(\mathbf{a}, \mathbf{b}) \& \mathrm{Fa} \& \forall \mathbf{x} \forall \mathbf{y}[\mathrm{Fx} \& \mathrm{Rxy} \rightarrow \mathrm{Fy}] \rightarrow \mathrm{Fb}$

Suppose $\mathbf{a}=\mathbf{b}$. Then, if Fa, Fb. Hence, with $\left(128_{\mathrm{n}}\right)$ :

$\left[\mathbf{a}=\mathbf{b} \vee \mathscr{F}_{\mathrm{n}}(\mathrm{R})(\mathbf{a}, \mathbf{b})\right] \& \mathrm{Fa} \& \forall \mathbf{x} \forall \mathbf{y}[\mathrm{Fx} \& \mathrm{Rxy} \rightarrow \mathrm{Fy}] \rightarrow \mathrm{Fb}$

$152_{\mathrm{n}}: \mathscr{F}_{\mathrm{n}}{ }^{=}(\mathrm{R})(\mathbf{a}, \mathbf{b}) \& \mathrm{Fa} \& \forall \mathbf{x} \forall \mathbf{y}\left[\mathscr{F}_{\mathrm{n}}{ }^{(\mathrm{R}}(\mathrm{R})(\mathbf{a}, \mathbf{x}) \& \mathrm{Fx} \& \mathrm{Rxy} \rightarrow \mathrm{Fy}\right] \rightarrow \mathrm{Fb}$

Suppose the antecedent, use $\left(144_{\mathrm{n}}\right)$, with $\mathscr{F}_{\mathrm{n}}{ }^{=}(\mathrm{R})(\mathbf{a}, \boldsymbol{\xi}) \& \mathrm{~F} \boldsymbol{\xi}$. Since Fa, by $\left(140_{\mathrm{n}}\right), \mathscr{F}_{\mathrm{n}}{ }^{=}(\mathrm{R})(\mathbf{a}, \mathbf{a}) \& \mathrm{Fa}$; i.e., a falls under $\mathscr{F}_{\mathrm{n}}{ }^{=}(\mathrm{R})(\mathbf{a}, \boldsymbol{\xi}) \& \mathrm{~F} \boldsymbol{\xi}$. Suppose, further, $\mathscr{F}_{\mathrm{n}}{ }^{=}(\mathrm{R})(\mathbf{a}, \mathbf{x}) \& \mathrm{Fx}$ and Rxy. Then, Fy, by hypothesis, and $\mathscr{F}_{\mathrm{n}}{ }^{=}(\mathrm{R})(\mathbf{a}, \mathbf{y})$, by $\left(137_{\mathrm{n}}\right) ;$ so, $\mathscr{F}_{\mathrm{n}}=(\mathrm{R})(\mathbf{a}, \boldsymbol{\xi}) \& \mathrm{~F} \boldsymbol{\xi}$ is hereditary. Hence, by $\left(144_{\mathrm{n}}\right)$ : Fb \& $\mathscr{F}_{\mathrm{n}}=(\mathrm{R})(\mathbf{a}, \mathbf{b})$.

Definition: Func $\mathrm{n}_{\mathrm{n}, \mathrm{n}}(\mathrm{R} \xi ; \boldsymbol{\eta}) \equiv \mathrm{df} \forall \mathbf{x} \forall \mathbf{y} \forall \mathbf{z}(\mathrm{Rxy} \& \mathrm{R} \mathbf{x z} \rightarrow \mathbf{y}=\mathbf{z})$

$242_{\mathrm{n}}: \mathrm{Func}_{\mathrm{n}, \mathrm{n}}(\mathrm{R} \xi ; \eta) \& \mathscr{F}_{\mathrm{n}}(\mathrm{R})(\mathbf{d}, \mathbf{n}) \& \mathrm{Rda} \rightarrow \mathscr{F}_{\mathrm{n}}{ }^{=}(\mathrm{R})(\mathbf{a}, \mathbf{n})$

$\left(123_{\mathrm{n}}\right)$, with $\mathscr{F}_{\mathrm{n}}=(\mathrm{R})(\mathbf{a}, \xi)$. We must show that, if $\mathrm{R} \xi ; \eta$ is $\mathrm{n}, \mathrm{n}-$ functional and Rda, then:

(i) $\forall \mathbf{x}\left[\mathrm{Rd} \mathbf{x} \rightarrow \mathscr{T}_{\mathrm{n}}=(\mathrm{R})(\mathbf{a}, \mathbf{x})\right]$

(ii) $\forall \mathbf{x} \forall \mathbf{y}\left[\mathrm{Rxy} \& \mathscr{F}_{\mathrm{n}}{ }^{\mathrm{n}}(\mathrm{R})(\mathbf{a}, \mathbf{x}) \rightarrow \mathscr{F}_{\mathrm{n}}{ }^{=}(\mathrm{R})(\mathbf{a}, \mathbf{y})\right]$

(ii) follows immediately from Theorem $137_{n}$. For the proof of (i), suppose that Rdx. Since $R(\xi ; \eta)$ is n,nfunctional and Rda, we have that $\mathbf{x}=\mathbf{a}$, whence $\mathscr{F}_{\mathrm{n}}=(\mathrm{R})(\mathbf{a}, \mathbf{x})$, by Theorem 139. Done.

243: $\operatorname{Func}_{\mathrm{n}, \mathrm{n}}(\mathrm{R} \xi ; \eta) \& \mathscr{F}_{\mathrm{n}}{ }^{=}(\mathrm{R})(\mathbf{a}, \mathbf{b}) \& \mathscr{F}_{\mathrm{n}}{ }^{=}(\mathrm{R})(\mathbf{a}, \mathbf{c}) \rightarrow\left[\mathscr{F}_{\mathrm{n}}{ }^{=}(\mathrm{R})(\mathbf{c}, \mathbf{b}) \vee \mathscr{F}_{\mathrm{n}}(\mathrm{R})(\mathbf{b}, \mathbf{c})\right]$

$\left(144_{\mathrm{n}}\right)$, with: $\mathscr{F}_{\mathrm{n}}{ }^{=}(\mathrm{R})(\boldsymbol{\xi}, \mathbf{b}) \vee \mathscr{F}_{\mathrm{n}}(\mathrm{R})(\mathbf{b}, \boldsymbol{\xi})$. We must prove, that, if $\mathrm{Func}_{\mathrm{n}, \mathrm{n}}(\mathrm{R} \xi ; \boldsymbol{\eta})$ and $\mathscr{F}_{\mathrm{n}}{ }^{=}(\mathrm{R})(\mathbf{a}, \mathbf{b})$ :

(i) $\mathscr{F}_{\mathrm{n}}=(\mathrm{R})(\mathbf{a}, \mathbf{b}) \vee \mathscr{F}_{\mathrm{n}}(\mathrm{R})(\mathbf{b}, \mathbf{a})$

(ii) $\forall \mathbf{x} \forall \mathbf{y}\left\{\operatorname{Rxy} \&\left[\mathscr{F}_{\mathrm{n}}{ }^{=}(\mathrm{R})(\mathbf{x}, \mathbf{b}) \vee \mathscr{F}_{\mathrm{n}}(\mathrm{R})(\mathbf{b}, \mathbf{x})\right] \rightarrow\left[\mathscr{F}_{\mathrm{n}}{ }^{=}(\mathrm{R})(\mathbf{y}, \mathbf{b}) \vee \mathscr{F}_{\mathrm{n}}(\mathrm{R})(\mathbf{b}, \mathbf{y})\right]\right\}$

(i) follows immediately, since $\mathscr{F}_{\mathrm{n}}=(\mathrm{R})(\mathbf{a}, \mathbf{b})$. Suppose, then, that $\mathrm{Rxy}$ and either $\mathscr{F}_{\mathrm{n}}{ }^{=}(\mathrm{R})(\mathbf{x}, \mathbf{b})$ or $\mathscr{F}_{\mathrm{n}}(\mathrm{R})(\mathbf{b}, \mathbf{x})$. If the latter, then $\mathscr{F}_{\mathrm{n}}(\mathrm{R})(\mathbf{b}, \mathbf{y})$, by Theorem $133_{\mathrm{n}}$. Suppose, then, that $\left.\mathscr{F}_{\mathrm{n}}{ }^{=} \mathrm{R}\right)(\mathbf{x}, \mathbf{b})$. Then either $\mathbf{x}=\mathbf{b}$ or $\mathscr{F}_{\mathrm{n}}(\mathrm{R})(\mathbf{x}, \mathbf{b})$. If $\mathbf{x}=\mathbf{b}$, then, since $\mathrm{Rxy}$, Rby, whence $\mathscr{F}_{\mathrm{n}}(\mathrm{R})(\mathbf{b}, \mathbf{y})$, by Theorem $131_{\mathrm{n}}$. But, if $\mathscr{F}_{\mathrm{n}}(\mathrm{R})(\mathbf{x}, \mathbf{b})$, then since Rxy and $\mathrm{R}(\boldsymbol{\xi} ; \boldsymbol{\eta})$ is $\mathrm{n}, \mathrm{n}$-functional, $\mathscr{F}_{\mathrm{n}}=(\mathrm{R})(\mathbf{y}, \mathbf{b})$, by Theorem 242. 


\section{Tree of Important Theorems \\ in the Proof of Theorem 263}

The following is a graphical representation of the dependencies among the main theorems used in Frege's proof of Theorem 263. Theorems in italics are general results concerning the ancestral. Uses of definitions or theorems which are immediate consequences thereof have been omitted. The chart and the list of theorems which follows should enable the reader to reconstruct Frege's proof of Theorem 263 without difficulty.

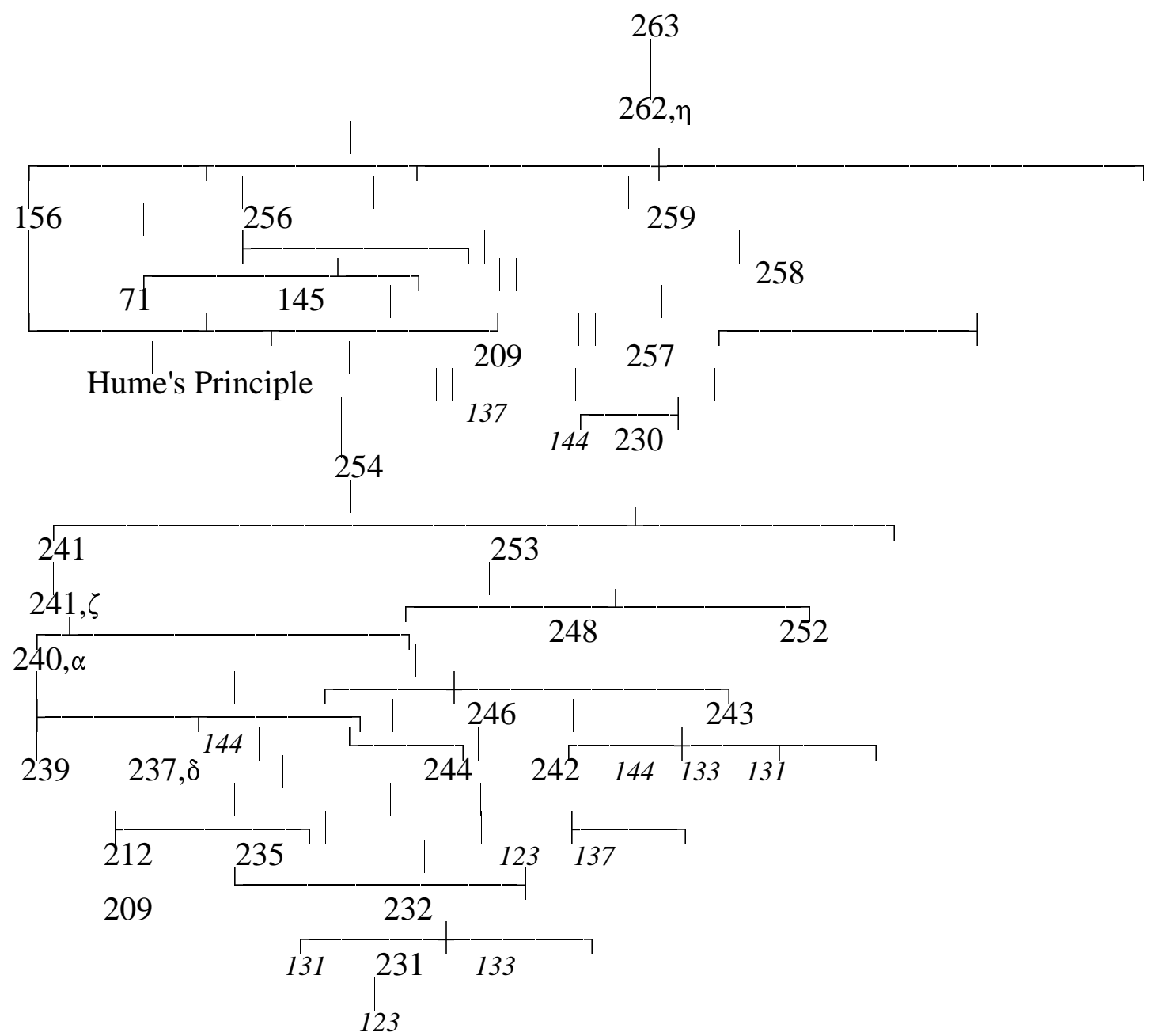




\section{Important Theorems in the Proof of Theorem 263}

263: $\exists \mathrm{Q}[\mathrm{Func}(\mathrm{Q}) \& \neg \exists \mathrm{x} . \mathscr{F}(\mathrm{Q})(\mathrm{x}, \mathrm{x}) \& \forall \mathrm{x}(\mathrm{Gx} \rightarrow \exists \mathrm{y} . \mathrm{Qxy}) \& \exists \mathrm{x} \forall \mathrm{y}(\mathrm{Gy} \equiv \mathscr{T}=(\mathrm{Q})(\mathrm{x}, \mathrm{y}))] \rightarrow \mathrm{Nx}: \mathrm{Gx}=\infty$ 262, ๆ: Func $(\mathrm{Q}) \& \neg \exists \mathrm{x} . \mathscr{F}(\mathrm{Q})(\mathrm{x}, \mathrm{x}) \& \forall \mathrm{x}(\neg \exists \mathrm{y} \cdot \mathrm{Qx}, \mathrm{y} \rightarrow \neg \mathscr{F}=(\mathrm{Q})(\mathrm{a}, \mathrm{x})) \rightarrow \mathrm{Nx}: \mathscr{F}=(\mathrm{Q})(\mathrm{a}, \mathrm{x})=$ $\mathrm{Nx}: \mathscr{F}=($ Pred $)(0, \mathrm{x})$

259: $\forall \mathrm{y} \forall \mathrm{z}\left\{\mathscr{F}^{\wedge}(\mathrm{Q} \pi \mathrm{R} ; \mathrm{a}, \mathrm{m})(\mathrm{y}, \mathrm{z}) \equiv \operatorname{Conv}\left[\mathscr{F}^{\wedge}(\mathrm{R} \pi \mathrm{Q} ; \mathrm{m}, \mathrm{a})\right](\mathrm{y}, \mathrm{z})\right\}$

258: $\mathscr{F}^{=}(\mathrm{R} \pi \mathrm{Q})(\mathrm{m}, \mathrm{a} ; \mathrm{n}, \mathrm{y}) \rightarrow \mathscr{F}^{=}(\mathrm{Q} \pi \mathrm{R})(\mathrm{a}, \mathrm{m} ; \mathrm{y}, \mathrm{n})$

257: $\mathscr{F}=(\mathrm{R} \pi \mathrm{Q})(\mathrm{m}, \mathrm{a} ; \mathrm{n}, \mathrm{y}) \& \forall \mathrm{z} \forall \mathrm{w}(\mathrm{Fzw} \rightarrow \forall \mathrm{u} \forall \mathrm{v}(\mathrm{Rzu} \& \mathrm{Qwv} \rightarrow$ Fuv $)) \&$ Fma $\rightarrow$ Fny

256: Func $(\mathrm{Q}) \& \forall \mathrm{y}(\neg \exists \mathrm{z} . \mathrm{Qy}, \mathrm{z} \rightarrow \neg \mathscr{T}=(\mathrm{Q})(\mathrm{a}, \mathrm{y})) \rightarrow \operatorname{Map}\left[\mathscr{T}^{\wedge}(\operatorname{Pred} \pi \mathrm{Q} ; 0, \mathrm{a})\right](\mathscr{T}=(\operatorname{Pred})(0, \xi)$, $\mathscr{T}=(\mathrm{Q})(\mathrm{a}, \xi))$

254: $\operatorname{Func}(\mathrm{R}) \& \operatorname{Func}(\mathrm{Q}) \& \neg \exists \mathrm{y}\left(\mathscr{F}^{=}(\mathrm{R})(\mathrm{m}, \mathrm{y}) \& \mathscr{F}(\mathrm{R})(\mathrm{y}, \mathrm{y})\right) \& \forall \mathrm{y}(\neg \exists \mathrm{z} \cdot \mathrm{Qy}, \mathrm{z} \rightarrow \neg \mathscr{F}=(\mathrm{Q})(\mathrm{a}, \mathrm{y})) \rightarrow$ $\operatorname{Map}\left[\mathscr{F}^{\wedge}(\mathrm{R} \pi \mathrm{Q} ; \mathrm{m}, \mathrm{a})\right]\left(\mathscr{F}^{=}(\mathrm{R})(\mathrm{m}, \xi), \mathscr{F}^{=}(\mathrm{Q})(\mathrm{a}, \xi)\right)$

253: $\operatorname{Func}(\mathrm{R}) \& \operatorname{Func}(\mathrm{Q}) \& \neg \exists \mathrm{y}\left[\mathscr{F}^{=}(\mathrm{R})(\mathrm{m}, \mathrm{y}) \& \mathscr{F}(\mathrm{R})(\mathrm{y}, \mathrm{y})\right] \rightarrow \operatorname{Func}\left(\mathscr{F}^{\wedge}(\mathrm{R} \pi \mathrm{Q} ; \mathrm{m}, \mathrm{a})\right)$

252: $\operatorname{Func}(R) \& \operatorname{Func}_{(\mathrm{Q})} \rightarrow \operatorname{Func}_{2,2}(\mathrm{R} \pi \mathrm{Q})$

248: $\operatorname{Func}_{2,2}(\mathrm{R} \pi \mathrm{Q}) \& \neg \exists \mathrm{x}\left[\mathscr{F}^{=}(\mathrm{R})(\mathrm{m}, \mathrm{x}) \& \mathscr{F}^{=}(\mathrm{R})(\mathrm{x}, \mathrm{x})\right] \rightarrow \operatorname{Func}\left(\mathscr{F}^{\wedge}(\mathrm{R} \pi \mathrm{Q} ; \mathrm{m}, \mathrm{a})\right)$

246: $\mathscr{F}_{2}=(\mathrm{R} \pi \mathrm{Q})(\mathrm{m}, \mathrm{a} ; \mathrm{b}, \mathrm{d}) \rightarrow \mathscr{T}^{=}(\mathrm{R})(\mathrm{m}, \mathrm{b})$

244: $\mathscr{F}_{2}(\mathrm{R} \pi \mathrm{Q})(\mathrm{m}, \mathrm{a} ; \mathrm{b}, \mathrm{d}) \rightarrow \mathscr{F}(\mathrm{R})(\mathrm{m}, \mathrm{b})$

243: $\operatorname{Func}(\mathrm{R}) \& \mathscr{T}^{=}(\mathrm{R})(\mathrm{m}, \mathrm{t}) \& \mathscr{T}^{=}(\mathrm{R})(\mathrm{m}, \mathrm{n}) \rightarrow\left[\mathscr{F}(\mathrm{R})(\mathrm{n}, \mathrm{t}) \vee \mathscr{T}^{=}(\mathrm{R})(\mathrm{t}, \mathrm{n})\right]$

242: $\operatorname{Func}(\mathrm{R}) \& \mathscr{F}(\mathrm{R})(\mathrm{d}, \mathrm{n}) \& \mathrm{Rda} \rightarrow \mathscr{T}^{=}(\mathrm{R})(\mathrm{a}, \mathrm{n})$

241: $\operatorname{Func}\left(\mathscr{F}^{\wedge}(\mathrm{R} \pi \mathrm{Q} ; \mathrm{m}, \mathrm{a})\right) \& \forall \mathrm{x}\left[\mathscr{F}^{=}(\mathrm{Q})(\mathrm{a}, \mathrm{x}) \rightarrow \exists \mathrm{y} \cdot \mathrm{Qxy}\right] \rightarrow \operatorname{Map}\left(\mathscr{F}^{\wedge}(\mathrm{R} \pi \mathrm{Q} ; \mathrm{m}, \mathrm{a})\right)\left(\mathscr{F}^{=}(\mathrm{R})(\mathrm{m}, \xi)\right.$, $\mathscr{T}=(\mathrm{Q})(\mathrm{a}, \xi))$

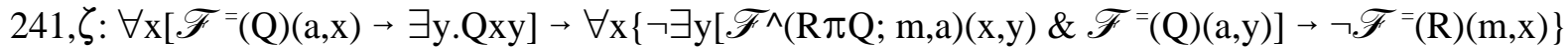

240, $\alpha: \forall \mathrm{x}\left[\neg \exists \mathrm{y} \cdot \mathrm{Qxy} \rightarrow \neg \mathscr{F}^{=}(\mathrm{Q})(\mathrm{a}, \mathrm{x})\right] \& \mathscr{F}^{=}(\mathrm{R})(\mathrm{m}, \mathrm{n}) \rightarrow \exists \mathrm{y} \cdot \mathscr{F}^{\wedge}(\mathrm{R} \pi \mathrm{Q} ; \mathrm{m}, \mathrm{a})(\mathrm{n}, \mathrm{y})$

239: $\exists \mathrm{x} . \mathscr{F}^{\wedge}(\mathrm{R} \pi \mathrm{Q} ; \mathrm{m}, \mathrm{a})(\mathrm{m}, \mathrm{x})$

237, $\mathrm{\delta}: \forall \mathrm{y}\left[\neg \exists \mathrm{z} . \mathrm{Qyz} \rightarrow \neg \mathscr{T}^{=}(\mathrm{Q})(\mathrm{a}, \mathrm{y})\right] \rightarrow \forall \mathrm{y} \forall \mathrm{z}\left\{\exists \mathrm{x} . \mathscr{F}^{\wedge}(\mathrm{R} \pi \mathrm{Q} ; \mathrm{m}, \mathrm{a})(\mathrm{y}, \mathrm{x}) \& \mathrm{Ryz} \rightarrow \exists \mathrm{x} . \mathscr{F}^{\wedge}(\mathrm{R} \pi \mathrm{Q} ;\right.$ $\mathrm{m}, \mathrm{a})(\mathrm{z}, \mathrm{x})\}$

235: $\mathscr{F}^{\wedge}(\mathrm{R} \pi \mathrm{Q} ; \mathrm{m}, \mathrm{a})(\mathrm{c}, \mathrm{d}) \rightarrow \mathscr{F}^{=}(\mathrm{Q})(\mathrm{a}, \mathrm{d})$

232: $\mathscr{F}(\mathrm{R} \pi \mathrm{Q})(\mathrm{m}, \mathrm{a} ; \mathrm{c}, \mathrm{d}) \rightarrow[\mathscr{F}(\mathrm{R})(\mathrm{m}, \mathrm{c}) \& \mathscr{F}(\mathrm{Q})(\mathrm{a}, \mathrm{d})]$

231: $\mathscr{F}(\mathrm{R} \pi \mathrm{Q})(\mathrm{m}, \mathrm{a} ; \mathrm{n}, \mathrm{b}) \& \forall \mathrm{x} \forall \mathrm{y} \forall \mathrm{z} \forall \mathrm{w}[\mathrm{Fxy} \& \mathrm{Rxz} \&$ Qyw $\rightarrow$ Fzw $] \& \forall \mathrm{x} \forall \mathrm{y}[\mathrm{Rmx} \&$ Qay $\rightarrow$ Fxy $] \rightarrow$ Fnb 230: $\forall \mathrm{x} \forall \mathrm{y}(\mathrm{Fxy} \rightarrow \forall \mathrm{z} \forall \mathrm{w}(\mathrm{Rxz} \&$ Qyw $\rightarrow \mathrm{Fzw})) \rightarrow \forall \mathrm{x} \forall \mathrm{y}(\mathrm{Fxy} \rightarrow \forall \mathrm{z} \forall \mathrm{w}[(\mathrm{R} \pi \mathrm{Q})(\mathrm{x}, \mathrm{y} ; \mathrm{z}, \mathrm{w}) \rightarrow \mathrm{Fzw}))$

212: $\forall \mathrm{y}\left[\neg \exists \mathrm{z} \cdot \mathrm{Qyz} \rightarrow \neg \mathscr{F}^{=}(\mathrm{Q})(\mathrm{a}, \mathrm{y})\right] \& \mathscr{F}^{=}(\mathrm{Q})(\mathrm{a}, \mathrm{d}) \& \mathscr{T}^{\wedge}(\mathrm{R} \pi \mathrm{Q} ; \mathrm{u}, \mathrm{v})(\mathrm{y}, \mathrm{d}) \& \mathrm{Ryz} \rightarrow$ $\exists \mathrm{x} . \mathscr{F}^{\wedge}(\mathrm{R} \pi \mathrm{Q} ; \mathrm{u}, \mathrm{v})(\mathrm{z}, \mathrm{x})$ 
209: $\mathscr{T}^{=}(\mathrm{R} \pi \mathrm{Q})(\mathrm{u}, \mathrm{v} ; \mathrm{c}, \mathrm{d}) \& \mathrm{R} \operatorname{co} \& \mathrm{Qdb} \rightarrow \mathscr{T}^{=}(\mathrm{R} \pi \mathrm{Q})(\mathrm{u}, \mathrm{v} ; \mathrm{o}, \mathrm{b})$

156: $\forall \mathrm{x}[\mathscr{F}=(\operatorname{Pred})(0, \mathrm{x}) \rightarrow \exists \mathrm{y} \cdot \operatorname{Pred}(\mathrm{x}, \mathrm{y})]$

145: $\neg \exists$ x. $[\mathscr{F}=($ Pred $)(0, \mathrm{x}) \& \mathscr{F}($ Pred $)(\mathrm{x}, \mathrm{x})]$

71: Func(Pred) 


\section{Notes}

1. Richard Dedekind, "The Nature and Meaning of Numbers", in Essays on the Theory of Numbers, tr. by W.W. Beman (New York: Dover, 1963). Was Sind? was first published in 1887; the second edition, in 1893. The former is Theorem 126; the latter, Theorem 132.

2. Gottlob Frege, Grundgesetze der Arithmetik (Hildesheim: Georg Olms, 1966). References are in the text, marked " $G g$ " with volume and section numbers.

3. Note that the first-order theory which contains Axiom V as its sole non-logical axiom is actually consistent. See Michael Dummett, Frege: Philosophy of Mathematics (Cambridge MA: Harvard University Press, 1992), p. 219; Terence Parsons, "On the Consistency of the First-Order Portion of Frege's Logical System", Notre Dame Journal of Formal Logic 28 (1987), pp. 161-8.

4. See my "The Development of Arithmetic in Frege's Grundgesetze der Arithmetik", forthcoming in the Journal of Symbolic Logic.

5. See George Boolos, "The Consistency of Frege's Foundations of Arithmetic", in On Being and Saying: Essays in Honor of Richard Cartwright (Cambridge MA: MIT Press, 1987), pp. 3-20.

6. I insert the bound variables in the definitions but will drop them when it causes no confusion.

7. Note that the definition does not say that $R \xi \eta$ is functional and is onto the Gs.

8. See "The Development of Arithmetic" for discussion of these. See also Gg I §66.

9. Gottlob Frege, The Foundations of Arithmetic, tr. by J.L. Austin (Evanston IL: Northwestern University Press, 1980). References are in the text, marked by "Gl" and a section number.

10. Frege does not have any special symbol for this concept, though he reads " $\mathscr{F}=(\operatorname{Pred})(0, \xi)$ " as " $\xi$ is a finite number [endliche Anzahl]". See Gg I §108.

11. The following is from $G g$ I $§ 144$. The translation is due to myself and Jason Stanley.

12. In connection with Frege's use of the word "associate", see $G g$ I $§ 66$.

13. From left-to-right, the axiom is proven as Theorem 218; from right-to-left, as Theorem 251.

14. Frege does, it should be said, also use the following trick, which explains why he defines ordered pairs as he does. Indeed, it is really too bad that his definition does not work. For certain purposes, when making use of ordered pairs, one needs, given a relation $R \xi \eta$, to define a concept $F \xi$ such that:

$$
\mathrm{F}[(\mathrm{a} ; \mathrm{b})] \equiv \mathrm{Rab}
$$

Frege's definition makes this extremely easy: For Rab just in case the extension of the relation $\mathrm{R} \xi \eta$ is a member of the ordered pair $\langle a ; b\rangle$, since the ordered pair is the class of all extensions of relations in which a stands to $b$. That is, where $\dot{\alpha} \dot{\varepsilon}$. $R \in \alpha$ is the extension of $R \xi \eta$ :

$$
[\dot{\alpha} \dot{\varepsilon} \cdot R \in \alpha \in(a ; b)] \equiv R a b
$$

$(\dot{\alpha} \dot{\varepsilon} . R \in \alpha$ is the double value-range of the relation $\mathrm{R} \xi \eta$. Note that Frege does not use ordered pairs to define the extension of a relation. See $G g$ I §36.)

15. I have translated Frege's definition into second-order logic, eliminating the reference to value-ranges.

16. This is derived by Frege from his definition: From right-to-left, it is Theorem 208; from left-to-right, Theorem 223. 
17. An affirmative answer would imply the definability of addition for transfinite cardinals in FA, which is, for reasons I shall not discuss, equivalent to the following:

$\exists F[N x: F x=N x: \neg F x \& N x: F x=N x: x=x]$

That is: It is equivalent to the theorem that the domain can be partitioned into two equinumerous classes each of which is equinumerous with the whole domain. The problematic case is that in which Choice fails, whence the domain can not be well-ordered.

It is, however, easy to prove this theorem in $\mathrm{FA}+\mathrm{OP}$ : Let $\mathrm{F} \xi$ be defined as $\exists \mathrm{x}[\xi=(\mathrm{x} ; 0)] ; \mathrm{G} \xi$ as $\exists \mathrm{x}[\xi=(\mathrm{x} ; 1)]$. Plainly, $\mathrm{F} \xi$ and $\mathrm{G} \xi$ are equinumerous with $\xi=\dot{\xi}$ and so with each other. Since $\forall \mathrm{x}(\mathrm{Gx} \rightarrow$ $\neg \mathrm{Fx}$ ), by the Schröder-Bernstein Theorem (which is provable in second-order logic), $\neg \mathrm{F} \xi$ is equinumerous with $\xi=\xi$.

18. See Theorem 232, to be mentioned below.

19. For proofs of the various theorems concerning the 2- and n-ancestrals, see Appendix II.

20. Note that not all functions intuitively given by induction can be defined in this way. Coupling can not be used to define functions when the recursion equations are of the form:

$$
\begin{aligned}
& \varphi(0)=\mathrm{a} \\
& \varphi(\mathrm{n}+1)=\mathrm{g}(\mathrm{n}, \varphi(\mathrm{n}))
\end{aligned}
$$

However, let $\mathrm{T} \xi \eta ; \zeta \tau$ be defined as:

$\operatorname{Pred}(\xi, \zeta) \& \tau=\mathrm{g}(\xi, \eta)$

It is not hard to show that $\mathscr{F}^{\wedge}[\mathrm{T} ; 0, \mathrm{a}](\xi, \eta)$ is functional and satisfies the recursion equations.

21. Frege was aware of this. See $G g$ II $§ 33:$ "'The sum of two numbers is determined by them'. The thought of the proposition [in question here] is most easily recognized in this expression, and it may be cited for this purpose, although the definite article in the subject actually anticipates the assertion of determination, and although the word 'sum' here is used differently than we will later use it in connection with [real] numbers. Namely, we here call [Nx:(Fx $\vee \mathrm{Gx})]$ the sum of $[\mathrm{Nx}: \mathrm{Fx}]$ and $[\mathrm{Nx}: \mathrm{Gx}]$, if no object falls both under the [F-] and under the [G-]concept. Also, infinite numbers hereby come into consideration. If we wanted to prove the proposition only for finite numbers, then another method would be more sensible". I presume he means this one.

22 . The fact that $\mathscr{F}^{\wedge}(\mathrm{R} \pi \mathrm{Q} ; \mathrm{m}, \mathrm{a})(\xi, \eta)$ is an order-isomorphism is a relatively obvious consequence of the way it is defined. But see Appendix I for a proof, which is not given by Frege. The proof is easy, given certain theorems he does prove. It is perhaps worth mentioning that Dedekind does not explicitly prove this result either.

23. For this reason, certain relations so defined are not defined inductively, in any natural sense, e.g., if the relation $R \xi \eta$ is dense. But let us ignore such complications.

24. Thus, by substitution:

$$
\begin{aligned}
\forall \mathrm{x}\left[\mathscr{T}^{=}\right. & (\operatorname{Pred})(0, \mathrm{x}) \rightarrow \exists \mathrm{y} . \operatorname{Pred}(\mathrm{x}, \mathrm{y})] \rightarrow \\
& \forall \mathrm{x}\{\mathscr{T}=(\mathrm{R})(\mathrm{m}, \mathrm{x}) \rightarrow \exists \mathrm{y}[\mathscr{F} \wedge(\mathrm{R} \pi \operatorname{Pred} ; \mathrm{m}, 0)(\mathrm{x}, \mathrm{y}) \& \mathscr{T}=(\text { Pred })(0, \mathrm{y})]
\end{aligned}
$$

Since the antecedent is a theorem of FA, we have, as a theorem of FA:

$$
\forall \mathrm{x}\{\mathscr{T}=(\mathrm{R})(\mathrm{m}, \mathrm{x}) \rightarrow \exists \mathrm{y}[\mathscr{F} \wedge(\mathrm{R} \pi \operatorname{Pred} ; \mathrm{m}, 0)(\mathrm{x}, \mathrm{y}) \& \mathscr{T}=(\operatorname{Pred})(0, \mathrm{y})]
$$

That is: For any relation $\mathrm{R} \xi \eta$ and any object $\mathrm{m}, \mathscr{F}^{\wedge}(\mathrm{R} \pi \operatorname{Pred} ; \mathrm{m}, 0)(\xi, \eta)$ is a relation whose domain is exactly the R-series beginning with $\mathrm{m}$ and whose range is contained in the natural numbers.

25. It is worth mentioning, too, that $\mathscr{F}^{\wedge}(\mathrm{Q} \pi$ Pred; 1,0$)(\xi . \eta)--$ the converse of $\mathscr{F}^{\wedge}(\operatorname{Pred} \pi \mathrm{Q} ; 0,1)(\xi, \eta)--$ is also, by $(241, \eta)$, a relation whose domain consists of all members of the Q-series beginning with 1 and whose range consists wholly of natural numbers, since every natural number has a successor. Note, too, that its range consists of all natural numbers and that $\mathscr{F}^{\wedge}(\mathrm{Q} \pi$ Pred; 1,0$)(\xi, \eta)$ is functional. Thus, $\mathscr{F}^{\wedge}(\mathrm{Q}$ $\pi$ Pred; 1,0$)(\xi, \eta)$ is a counterexample to a converse of Theorem $248: \mathscr{T} \wedge(\mathrm{Q} \pi \mathrm{R} ; \mathrm{m}, \mathrm{n})(\xi, \eta)$ may be a function, even if $(\mathrm{Q} \pi \mathrm{R})(\xi, \eta ; \zeta, \tau)$ is not a 2,2-function. It is a nice question whether some general, informative theorem can be formulated concerning the conditions $\mathrm{Q} \xi \eta$ and $\mathrm{R} \xi \eta$ must satisfy if 
$\mathscr{F}^{\wedge}(\mathrm{R} \pi \mathrm{Q} ; \mathrm{m}, \mathrm{a})(\xi, \eta)$ is to be functional.

26. Viz.: Suppose that $\mathrm{R} \xi \eta$ and $\mathrm{Q} \xi \eta$ are functional; suppose that $(\mathrm{R} \pi \mathrm{Q})(\mathrm{x}, \mathrm{y} ; \mathrm{z}, \mathrm{w})$ and $(\mathrm{R} \pi \mathrm{Q})(\mathrm{x}, \mathrm{y} ; \mathrm{u}, \mathrm{v})$. Then, by the definition of coupling, Rxz and Rxu, and Qyw and Qyv. Since R $\xi \eta$ and $Q \xi \eta$ are functions, $\mathrm{z}=\mathrm{u}$ and $\mathrm{w}=\mathrm{v}$. QED.

Frege's own proof consists in the application of the definition of 'Func' to yield:

Func(R) \& Func(Q) \& Rco \& Rce \& Qda \& Qdi $\rightarrow \mathrm{o}=\mathrm{e} \& \mathrm{a}=\mathrm{i}$

He then applies the ordered pair axiom (Theorem 251) to get:

Func $(R) \&$ Func $(Q) \&$ Rco \& Rce \& Qda \& Qdi $\rightarrow(\mathrm{o} ; \mathrm{a})=(\mathrm{e} ; \mathrm{i})$

This is Frege's Theorem 251, $\alpha$. The remainder of the proof consists in the introduction of free variables "A", "D", and "E" for the ordered pairs, which turns out to be exceedingly tedious.

27. Gottlob Frege, Begriffsschrift, eine der arithmetischen nachgebildete Formelsprache des reinen Denkens, first published in 1879, reprinted in Begriffsschrift und andere Aufsätze, ed. by Ignacio Angelelli (New York: Georg Olms, 1988). For an English translation, see Frege and Gödel: Two Fundamental Texts in Mathematical Logic, tr. and ed. by J. van Heijenoort (Cambridge MA: Harvard University Press, 1970).

One might wonder if the fact that this theorem is not used in the proofs of the axioms of arithmetic does not indicate something about how many of the proofs of the theorems of Grundgesetze Frege had in 1879. However, Wright does use Theorem 133 in his reconstruction of the proof that every natural number has a successor, and his proof closely follows Frege's suggestions in Grundlagen: The proof given in Grundgesetze is somewhat different. Whether Theorem 133 is needed for the Grundlagen version of the proof is another question, but we are unlikely, at this point, to be able to establish anything very definitive about the date of Frege's discovery of Theorem 263.

28. See again "The Development of Arithmetic".

29. The corresponding result in question is Theorem 327 , which states that the number of a concept $F \xi$ is finite if:

$$
\exists \mathrm{Q} \exists \mathrm{x} \exists \mathrm{y}\left\{\operatorname{Func}(\mathrm{Q}) \& \neg \mathscr{T}(\mathrm{Q})(\mathrm{y}, \mathrm{y}) \& \forall \mathrm{z}\left[\mathrm{Fz} \equiv \mathscr{F}^{=}(\mathrm{Q})(\mathrm{x}, \mathrm{z}) \& \mathscr{F}^{=}(\mathrm{Q})(\mathrm{z}, \mathrm{y})\right]\right\}
$$

Indeed, Frege defines:

$$
\operatorname{Btw}(\mathrm{Q} \xi \eta ; \mathrm{a}, \mathrm{b})(\mathrm{x}) \equiv \mathrm{df} \operatorname{Func}(\mathrm{Q}) \& \neg \mathscr{F}(\mathrm{Q})(\mathrm{b}, \mathrm{b}) \& \mathscr{F}=(\mathrm{Q})(\mathrm{a}, \mathrm{x}) \& \mathscr{F}=(\mathrm{Q})(\mathrm{x}, \mathrm{b})
$$

Frege reads "Btw(Q;a,b)(x)" as "x belongs to the Q-series running from a to b", but I write it as I do because it seems more intuitive to read it as " $\mathrm{x}$ is between $\mathrm{a}$ and $\mathrm{b}$ in the Q-series" or just " $\mathrm{x}$ is Q-between $\mathrm{a}$ and $\mathrm{b} "$. Theorem 327 is then:

$$
\exists \mathrm{Q} \exists \mathrm{x} \exists \mathrm{y} \forall \mathrm{z}[\mathrm{Fz} \equiv \mathrm{Btw}(\mathrm{Q} ; \mathrm{x}, \mathrm{y})(\mathrm{z})] \rightarrow \mathscr{T}=(\operatorname{Pred})(0, \mathrm{Nx}: \mathrm{Fx})
$$

The converse of Theorem 327 is Theorem 348.

30. For further discussion of Frege's interest in finitude and infinity, see my "The Finite and the Infinite in Frege's Grundgesetze der Arithmetik", forthcoming in M. Schirn, ed., Philosophy of Mathematics Today (Oxford: Oxford University Press, 199?).

31. Not that this is what Frege had in mind, but this result is the central theorem needed in the proof that an inner model for Fregean Arithmetic is definable in Fregean Arithmetic. The first-order domain consists of the natural numbers, together with Endlos. This result implies that the relativization of Hume's Principle to that domain is a theorem of Fregean Arithmetic, and it is easy to see that the restriction of each instance of comprehension is also a theorem.

32. For, if some natural number precedes zero, then $\mathrm{Px} 0$ and $\mathscr{F}=(\mathrm{P})(0, \mathrm{x})$, whence $\mathscr{F}(\mathrm{P})(0,0)$. And, if $\mathrm{Pxz}$ and Pyz, for natural numbers $\mathrm{x}, \mathrm{y}, \mathrm{z}$, then, since $\mathscr{T}=(\mathrm{P})(0, \mathrm{x}), \mathscr{F}=(\mathrm{P})(0, \mathrm{y})$, and $\mathrm{P} \xi \eta$ is functional, we have, by Theorem 243 , that either $\mathscr{F}(\mathrm{P})(\mathrm{x}, \mathrm{y})$ or $\mathscr{F}(\mathrm{P})(\mathrm{y}, \mathrm{x})$, or $\mathrm{x}=\mathrm{y}$. But, if the former, since Pxz, by Theorem $242, \mathscr{F}=(\mathrm{P})(\mathrm{z}, \mathrm{y})$; and, since Pyz, $\mathscr{F}(\mathrm{P})(\mathrm{y}, \mathrm{y})$. Similarly, if $\mathscr{F}(\mathrm{P})(\mathrm{y}, \mathrm{x})$, then $\mathscr{F}(\mathrm{P})(\mathrm{x}, \mathrm{x})$. Hence $\mathrm{x}=\mathrm{y}$.

Conversely, the Dedekind-Peano Axioms imply these. The only one we must prove is (2). We proceed by induction. If $\mathscr{F}(\mathrm{P})(0,0)$, then, by Frege's Theorem 124, for some $\mathrm{x}$, Px0. Suppose $\neg \mathscr{F}(\mathrm{P})(\mathrm{x}, \mathrm{x})$, x a natural number, and Pxy. Suppose $\mathscr{F}(\mathrm{P})(\mathrm{y}, \mathrm{y})$. Then, we have the following 
strengthening of Theorem 124, Theorem 141:

$\mathscr{F}(\mathrm{Q})(\mathrm{a}, \mathrm{b}) \rightarrow \exists \mathrm{x}[\mathrm{Qxb} \& \mathscr{F}=(\mathrm{Q})(\mathrm{a}, \mathrm{x})]$

Hence, for some $\mathrm{z}$, Pzy and $\mathscr{T}^{=}(\mathrm{P})(\mathrm{y}, \mathrm{z})$. But $\mathrm{P} \xi \eta$ is one-one, so $\mathrm{z}=\mathrm{x}$.; so $\mathscr{T}=(\mathrm{P})(\mathrm{y}, \mathrm{x})$; but Pxy, so $\mathscr{F}(\mathrm{P})(\mathrm{x}, \mathrm{x})$. Contradiction.

33. I should like to thank George Boolos, Michael Dummett, Mathieu Marion, and Jason Stanley for their advice and criticism. 